\title{
Application of Improved Accelerated Random Search Algorithm for Structural Damage Detection
}

\author{
Lyes Boubakir and Noureddine Touat \\ Applied Mechanics Laboratory - University of Science and Technology, Houari Boumediene, BP 32, El-alia, \\ 16111, Bab Ezzouar, Algiers, Algeria.
}

\begin{abstract}
Mounir Kharoubi
Laboratoire de Mécanique et Structures, Mechanical engineering department, Université 08 Mai 1945, Guelma, Algeria.
\end{abstract}

\author{
Noureddine Benseddiq \\ Lille Mechanics Laboratory - University of Science and Technology of Lille, France, 2 - Rue de la Recherche BP \\ 90179 - 59653 Villeneuve d'Ascq Cedex, Lille, France.
}

\section{(Received 12 December 2014; accepted 17 June 2016)}

Finite element (FE) model updating technique belongs to the class of inverse problems in classical mechanics. According to the continuum damage mechanics, damage is represented by a reduction factor of the element stiffness and mass. The objective of the optimization problem is to minimize the difference between measured and numerical FE vibration data. In this study a new method is presented for structural damage detection called Improved Modified Accelerated Random Search algorithm (IMARS). The algorithm uses model updating procedure to detect damages in a decoupled fashion. First, detecting the location and the number of damaged elements is evaluated by multi-run process. Knowing damage number, the quantification step is then applied using simple computing procedure. The effectiveness of the algorithm is first tested on mathematical benchmark functions. The algorithm is then applied in damage detection of 2D beam structure and 2D truss structure. These two cases have different boundary conditions and different damage scenarios. The simulated experimental modal data have been taken as reference values. A real cantilever beam with experimental modal parameters is used to validate the proposed method for real single and double damages. Results show that the proposed method is accurate and robust in structural damage identification.

\section{INTRODUCTION}

Structural damage identification has gained increasing attention from the scientific and engineering communities because the unpredicted structural failure may cause catastrophic, economic, and human life loss.

It is common understanding that four steps of damage identification are possible as proposed by Rytter. ${ }^{1}$ The first step includes the analysis of damage symptoms followed by damage location analysis in the second step. The objective in step three is to quantify the extent of the damage, for example, with respect to the size and the geometry of a crack. In practice, these three steps are covered and implemented in present nonmodel and non-vibration based testing and monitoring procedures like in ultrasonic, electromagnetic, thermography or radiation methods which will not be addressed in this paper. The final step includes the prediction of remaining safety and service life of the structure.

The damage identification technique is crucial to maintain safety and integrity of structures. Most non-destructive damage identification methods can be categorized as either local or global damage identification techniques. ${ }^{2}$ Local damage identification techniques, such as ultrasonic methods and X-ray methods, require that the vicinity of damage is known a priori and readily accessible for testing, which cannot be guaranteed for most cases in civil or aerospace engineering. Hence, the vibration-based damage identification method as a global damage identification technique is developed to overcome these difficulties.

The fundamental idea for vibration-based damage identification is that the damage induced changes in the physical properties (mass, damping, and stiffness) will cause detectable changes in modal properties (natural frequencies, mode shapes).

The dynamic characteristics of a structure include natural frequencies, mode shapes, frequency response functions (FRFs), etc. ${ }^{2,3}$ Many researchers worked with the first two types of dynamic data, ${ }^{4-7}$ because modal analysis data is easy to obtain, and some dealt with the FRF data. ${ }^{8-10}$ Other researchers used static data in damage detection, ${ }^{11,12}$ or combined static responses and dynamic data. ${ }^{13,14}$ Cawley and Adams ${ }^{15}$ used changes in natural frequencies to identify damage in composite materials. Farrar et al. ${ }^{16}$ implemented the shifts in natural frequencies to identify damage on an I-40 bridge and noted that shifts in the natural frequencies were not adequate for detecting damage of small faults. Lei et al proposed an algorithm for detecting structural damage with limited input and output measurement signals. ${ }^{49}$ Salawu $^{17}$ presented an extensive review of publications before 1997 dealing with the detection of damages through frequency changes. The 
author has stated that the formulation of objective function using an adequate combination of vibrational data (frequencies and mode shape) contributes more in the process of damage identification. Further applications of natural frequencies include spot welding ${ }^{18}$ and beam-like structures. ${ }^{19,20}$ The use of natural frequencies in damage detection necessitates the development of models that can accurately predict natural frequencies. Salawu ${ }^{21}$ established a global damage integrity index, based on a weighted ratio of the natural frequencies of damaged to undamaged structures. The weights were used to specify the sensitivity of each mode to damage. The author, in the same reference, indicates that the direct use of mode shape change can only roughly localize the damage, and in order to precisely localize the damage, the mode shape-based methods have to rely on natural frequency data. Other methods use FRF measurements directly, as opposed to the modal data extracted from the FRF measurements. ${ }^{22,23}$ The authors argued that the FRF data can provide much more information on damage in a desired frequency range compared to modal data that is extracted with errors from a very limited range around resonance.

Computational model updating techniques are used to adjust selected parameters of finite element models in order to make the models compatible with experimental data. ${ }^{3,24,25}$ This is done by minimizing the differences (residuals) of analytical and experimental data by numerical optimization procedures. There are two approaches used in finite-element-model updating: direct methods and iterative methods. ${ }^{26}$ Direct methods, which use the modal properties, are computationally efficient to implement and reproduce the measured modal data exactly, but they do not take into account the physical parameters that are updated. Iterative procedures use changes in physical parameters to update the finite element models and, thereby, generate models that are physically realistic. For long-time updating techniques have also been investigated with regard to their ability to localize and quantify structural damage. ${ }^{27-32}$ Occurrence of damage in structures will change the static and dynamic characteristics such as displacement, strain, natural frequencies, damping loss factors, mode shapes, and frequency response function (FRF). In the last years, several authors have studied modal updating and structural health monitoring. For example, de Roeck and co-workers ${ }^{30-32}$ have proposed new methodologies for solving damage detection inverse problems. The authors have used the Coupled Local Minimizers (CLM) method for model updating and damage detection, ${ }^{30,31}$ and compared the CLM method to a differential evolution algorithm for dynamic damage detection problems. ${ }^{32}$

Among iterative procedures, many stochastic optimization methods have been used in model updating and damage detection. ${ }^{26-33}$ Levin and Lieven ${ }^{26}$ introduced the genetic algorithm (GA) and simulated annealing for finite-element-model updating. Marwala ${ }^{34-36}$ successfully applied three separate genetic algorithms to minimize the distance between the measured data and the finite-element predicted data. Touat et $\mathrm{al}^{37}$ proposed an accelerated random search algorithm for model updating. The Accelerated Random search (ARS) algorithm ${ }^{38}$ has been developed to accelerate the stochastic search process for mathematical optimisation problems. The algorithm has shown a very good ability at hill climbing for optimum solutions, and its convergence speed is very fast. ${ }^{37,38}$ In damage detection, Borges et $\mathrm{al}^{38}$ have presented a structural damage identification method based on genetic algorithm and vibrational data. Meruane and Heyle ${ }^{39}$ presented damage detection with parallel genetic algorithm and operational modes. Other researchers have given special attention to genetic algorithm by hybridization with others algorithms. ${ }^{40-43}$ This paper proposes a new structural damage detection algorithm that uses a new competitive version of ARS algorithm. The algorithm is called the Improved Modified Accelerated Random Search algorithm (IMARS). This algorithm is combined with a damage detection technique based on runtime eigensensitivities to develop the new damage detection procedure. The new procedure exploits the constancy of frequencies and mode shapes when updated parameters are varied for each element of the stiffness and mass matrices considering several runs of the algorithm.

In section 3, the proposed algorithm is presented and compared to classical version of ARS by benchmark functions optimization. The damage detection formulation for optimization problem by defining the multi-objective function in modal domain is given in section 3 . The effectiveness of the proposed method is tested for damage detection of a simulated dynamic beam structure and truss structure, and the simulated experimental modal data are taken as reference values. Finally, a real cantilever beam with experimental modal parameters is used to validate the proposed method for real single and double damages. The IMARS procedure has been shown to be efficient, robust and giving good results in reduced time.

\section{PROPOSED ALGORITHM}

\subsection{ARS Algorithm}

The performance of commonly used (local) optimization methods usually depends on the starting values for the parameters and the solution often requires prohibitively many function evaluations. In order to overcome problems of local optimality and to thoroughly explore the variable domain, the accelerated random search (ARS) algorithm ${ }^{37}$ has been employed for minimizing unconstrained optimization problems. The ARS algorithm is for convenience outlined in the following.

Let us consider the general unconstrained optimization problem:

$$
\begin{aligned}
& \text { Find } x \in D \\
& \text { Such that } f(x) \rightarrow \text { min; }
\end{aligned}
$$

where $x$ is the vector of $n$ design variables $x_{i}, f(x)$ is the objective function and $D$ is the search space.

This problem can be solved using the Pure Random Search (PRS) algorithm (which is the Monte Carlo classical optimization technique) in the following way:

Generate a random vector $\left\{X_{i}\right\}_{i=1}^{n}$ with uniform distribution on $D$, trivial

$$
\text { Compute } M_{n}=\max \left\{f\left(X_{i}\right): i=1, \ldots, n\right\}
$$

The convergence of this algorithm (PRS) depends on several parameters (e.g. the type of problem to be optimized, its dimension, the size of the space search ...) but it is very slow 
in most cases of optimization (e.g., where standard calculusbased methods are not applicable, where the dimension of function is very large, etc.). ${ }^{37}$

The Accelerated Random Search algorithm (ARS) is a stochastic search methodology ${ }^{37}$ presented to improve the convergence of the PRS algorithm and to accelerate the random search to obtain the global optimum in a reduced time.

In order to solve (1), Appel et al. ${ }^{37}$ assumed that $D$ is the d-dimensional unit hyper-cube $[0,1]^{d}$. Moreover, the closed ball of radius $r$ centred at $x,\{y \in D\}:,\|x-y\| \leq r$, is denoted by $B(x, r)$, where $\|$. $\|$ is the sup-norm in $D$. Let a contraction factor $c>1$ and a precision threshold $\rho>0$ be given. The ARS algorithm is formulated in the following way:

Step 0 . Set $k=1$, and $r_{1}=1$. Generate $X_{i}$ from a uniform distribution on $D$.

Step 1. Given $X_{k} \in D$ and $r_{k} \in(0,1]$, generate, $Y_{k}$ from a uniform distribution on $B\left(X_{k}, r_{k}\right)$

Step 2. If $f\left(Y_{k}\right)>f\left(X_{k}\right)$, then let $X_{k+1}=Y_{k}$ and $r_{k+1}=1$.

Else if $f\left(Y_{k}\right) \leq f\left(X_{k}\right)$, then let $X_{k+1}=X_{k}$ and $r_{k+1}=r_{k} / c$

If $r_{k+1}<\rho$, then $r_{k+1}=1$.

Increment $k=k+1$ and go to step 1 .

Step 2 implies that in case the new candidate $Y_{n}$ is not better than the current $X_{n}$, the radius of the ball shrinks, and thus the search space shrinks. On the other hand, if $Y_{n}$ delivers a better function value than $X_{n}$, the search space is reinitialized to the whole domain $D$. Since the radius is decreased whenever the new candidate is not better than the current candidate, the search space will shrink quickly until sampling happens only in the neighbourhood of a local optimum. After a certain number of shrinks, the search space is reinitialized to the whole space, and thus escape from local optima is possible. The ARS algorithm may be readily applied to problems defined over a general metric space, for example, to combinatorial optimization problems and to optimization problems whose domains involve complicated constraints (e.g. the case of structural damage detection).

\subsection{Improved Modified ARS (IMARS)}

A novel version of ARS algorithm is proposed in this section and called improved modified accelerated random search algorithm (IMARS). It is proposed to improve the performance of the initial version of ARS.

In the first step, generate an initial random vector $\left\{X_{i}\right\}_{i=1}^{n}$ from a uniform distribution on $D$ and compute its objective function. In the second step, generate two new vectors $Y_{n 1}$, $Y_{n 2}$ from a uniform distribution on $B\left(X_{n}, r_{n}\right)$ and compute their correspondent objective functions. The smallest objective function value of two vectors is then considered in step 3. If the selected solution is better than the initial one, one replaces the initial solution by the selected one, and so on.

A precise statement of IMARS is implemented as follows:

Step 0 . Set $k=1$, and $r_{1}=1$. Generate $X_{k}$ from a uniform distribution on $D$.
Step 1. Given $X_{k} \in D$ and $r_{k} \in(0,1]$, generate, $Y_{k 1}, Y_{k 2}$ from a uniform distribution on $B\left(X_{k}, r_{k}\right)$.

Step 2. If $f\left(Y_{k 1}\right) \geq f\left(Y_{k 2}\right)$, then let $X_{i}=Y_{k 1} ; f_{i}=f\left(Y_{k 1}\right)$ and $r_{k+1}=1$

Else if $f\left(Y_{k 1}\right) \leq f\left(Y_{k 2}\right)$, then let $X_{i}=Y_{k 2} ; f_{i}=$ $f\left(Y_{k 2}\right)$ and $r_{n+1}=1$

Step 3. If $f_{i} \geq f\left(X_{k}\right)$, then let $X_{k+1}=X_{i}$ and $r_{k+1}=1$

Else if $f_{i}<f\left(X_{k}\right)$, then let $X_{k+1}=X_{k}$ and $r_{k+1}=$ $r_{k} / c$

If $r_{k+1}<\rho$, then $r_{k+1}=1$

Increment $k=k+1$ and go to step 1

The changes to generate IMARS algorithm, despite simplicity, actually present better results. According to the ARS algorithm, two new start points are generated in the first step of IMARS. This phase is proposed to give more chance to IMARS to better explore the space search and accelerate the optimization process.

The IMARS algorithm applies, similar to simulated annealing (SA) ${ }^{44}$ and evolutionary algorithms (EA), ${ }^{45}$ a neighbourhood search strategy. However, in contrast to SA and EA, IMARS never accepts solutions that are worse than the current solution. The solution improves or stays at least the same from one iteration to another. IMARS tries to overcome local optimality by reinitializing the search radius to the whole variable domain while SA and EA accept worse solutions in order to escape from local optima. SA and EA restrict the search space to a set of neighbouring solutions and the algorithms stop after several unsuccessful improvement trials. IMARS on the other hand restarts the search similar to a multi-start optimization procedure and continues the search until the predefined number of iterations has been reached or some other stopping criterion has been met. Thus, IMARS explores the parameter domain better and is for this reason applied in this paper.

\subsection{Performance of the Proposed Algorithm}

In this section, the new algorithm is compared to the ARS algorithm. Five functions are used to test the proposed algorithm; these functions are selected from the first publication of $\mathrm{ARS}^{37}$ as listed in Table 1. Firstly, PRS was run for $1,000,000$ iterations; only the obtained minimal function value is considered. After that, ARS was executed several times until obtaining the lower value. The number of iterations needed for that, is counted. This value is lower than that obtained by PRS algorithm. The next step consists to run IMARS with the same number of iterations obtained by ARS to determine the minimal function value. The process is repeated 100 times for eventual confirmation. Evidently from Table 1, IMARS algorithm significantly outperforms ARS algorithm in each of these experiments.

In the second part, the proposed algorithm, IMARS, is tested by four benchmark functions. These functions have simultaneously $30,30,30$, and 100 dimensions such that they may have numerous local minimums. They are often utilized to test optimization methods and are listed in Table 2. These functions are to be minimized and are adopted from Leung and Wang. ${ }^{45}$ 


\begin{tabular}{l}
\hline \hline Table 1. Standard test functions. \\
\begin{tabular}{|c|c|c|c|c|}
\hline Test function & $\begin{array}{c}\text { Number of } \\
\text { iterations }\end{array}$ & $\begin{array}{c}\text { Mean function } \\
\text { value (IMARS) }\end{array}$ & $\begin{array}{c}\text { Mean function } \\
\text { value (ARS) }\end{array}$ & $\begin{array}{c}\text { Global } \\
\text { optimum value }\end{array}$ \\
\hline Rosenbrock & 1256 & $2.995 \mathrm{e}-13$ & $9.219 \mathrm{e}-12$ & 0 \\
\hline Himmelblau & 188 & $2.133 \mathrm{e}-09$ & $2.479 \mathrm{e}-07$ & 0 \\
\hline Freudenstein-Rooth & 1693 & $6.006 \mathrm{e}-12$ & $8.664 \mathrm{e}-09$ & 0 \\
\hline Jennrich-Sampson & 438 & 124.3621 & 124.3626 & 124.362 \\
\hline Griewank & 539 & $7.993 \mathrm{e}-15$ & $3.253 \mathrm{e}-12$ & 0 \\
\hline
\end{tabular}
\end{tabular}

Table 2. Four benchmark functions to test the proposed algorithm.

\begin{tabular}{|c|c|}
\hline Benchmark function & Feasible solution space \\
\hline$f_{1}\left(x_{i}\right)=\sum_{i=1}^{N}-x_{i} \sin (\sqrt{|x|})$ & {$[-500,500]^{N=30}$} \\
\hline$f_{2}\left(x_{i}\right)=\sum_{i=1}^{N}\left(x_{i}^{2}-10 \cos \left(2 \pi x_{i}\right)+10\right)$ & {$[-5.12,5.12]^{N=30}$} \\
\hline$f_{3}\left(x_{i}\right)=\sum_{i=1}^{N} x_{i}^{4}+\operatorname{rand}$ & {$[-1.28,1.28]^{N=30}$} \\
\hline$f_{4}\left(x_{i}\right)=\frac{1}{N} \sum_{i=1}^{N}\left(x_{i}^{4}-16 x_{i}^{2}+5 x_{i}\right)$ & {$[-5,5]^{N=100}$} \\
\hline
\end{tabular}

The mean function values of 20 independent simulations are shown in Table 3. The results given by IMARS are compared with two other algorithms presented in ref. ${ }^{14}$ and ref. ${ }^{46}$ The proposed algorithm always has the best results. It has better mean function values for all experiments than those obtained in ref. ${ }^{14}$ and ref. ${ }^{46}$ This shows that the proposed algorithm has better hill-climbing ability. Hence, it could avoid the premature convergence and find the global optimum value or the near global optimum value. The number of function evaluation is the number of function call to evaluate its value during the execution of the algorithm, and it is often used to represent the execution time of the algorithm. By comparing these results, the present algorithm has much small number of function evaluation, except for $f_{3}$ when the result of ref. ${ }^{14}$ is better than IMARS, but the mean function evaluation is much good than ref. ${ }^{14}$

\section{DAMAGE DETECTION}

\subsection{Objective Function}

Model updating method converts damage detection problem to an optimization problem. ${ }^{3,27}$ Each optimization problem is defined by its variables, feasible search area, constraints, and cost function. Variables present the parameter vector grouping damage extent factor of each element of the structure. The search area is the variation interval of damage extent factor. Cost function which indeed could be considered as the most important part, is a criterion to assess different solutions. In this regard, modal-domain properties including natural frequencies and Modal-Assurance-Criterion (MAC) are common criteria where the latter depicts the correlation of mode shapes.

Two different objective functions will be considered in the present study. The natural frequency criterion $J_{\omega}$, is inspired from the work of Kwon and Lin ${ }^{45}$ by considering the second order formulation

$$
J_{\omega}=\sum_{k=1}^{n}\left(\frac{\omega_{k}^{m}-\omega_{k}^{a}}{\omega_{k}^{m}}\right)^{2} \rightarrow \min
$$

where $\omega_{k}$ are natural frequencies, superscripts $m$ and $a$ represent measured and analytical data, and $n$ is the number of first modes used.

The modal assurance criterion (MAC) is verified by the following expression given $\mathrm{in}^{31,48}$

$$
J_{M A C}=\sum_{k=1}^{n} \mid \Gamma(I)-\Gamma\left(M A C\left(\phi_{k}^{m}, \phi_{k}^{a}\right) \mid \rightarrow \min ;\right.
$$

where $\Gamma(I)$ is the trace of the identity matrix, and, the MAC is defined as

$$
M A C_{j k}=\frac{\left|\left(\phi_{j}^{m}\right)^{T}\left(\phi_{k}^{a}\right)\right|^{2}}{\left(\left(\phi_{j}^{m}\right)^{T}\left(\phi_{j}^{m}\right)\right)\left(\left(\phi_{k}^{a}\right)^{T}\left(\phi_{k}^{a}\right)\right)} ;
$$

$\phi^{m}$ and $\phi^{a}$ are measured and analytical normalized mode shape vectors, $T$ stands for the transpose of a vector.

The weighting objectives method is applied to transform the problem into a scalar optimization formulation. The objective function $\Psi$ to be minimized takes the form

$$
\Psi=W_{\omega} J_{\omega}+W_{M A C} J_{M A C}
$$

where $W_{\omega}$, and $W_{M A C}$ are weighting coefficients, representing the relative importance of the criteria $J_{\text {omega }}$ and $J_{M A C}$, and to have compatible contribution to the objective function, the displacement terms and natural frequency terms in Eq. (5) should be of the same order of magnitude. The selection of the weighting factors is difficult since the relative importance among the objective terms is not obvious. An appropriate choice of these parameters can improve results significantly. Therefore, relative weights of natural frequencies and mode shapes should be chosen carefully. ${ }^{23,47}$ Since natural frequencies are more accurately measured than mode shapes, the weighting value corresponding to natural frequencies $W_{\omega}$ has been set higher than the weighting coefficient of mode shapes $W_{M A C}$. These factors depend also on the number of measured modes taken for each analysed structure. In this work, the weighting coefficients have been selected after several tests and several runs of the updating process, starting with weighting proposition given in, ${ }^{47}$ and adjusting it in order to obtain the best value of the objective function.

The optimization parameters of the damage detection problem are model correction factors (parameters), affecting the simulation results $\omega_{k}^{a}$ and $\phi_{k}^{a}$.

The objective function is constructed to combine the effect of natural frequencies and mode shapes when evaluate the fitness of each parameter (model parameters of the structure) is evaluated. When one obtains the best solution of the problem by estimating the objective functions $J_{\omega}$ and $J_{M A C}$, its value should be equal to zero for each term of the summation.

\subsection{Damage Detection Procedure}

The characteristic equation of a dynamic damaged structure can be expressed as

$$
(K-\Delta K) \phi_{i}-\tilde{\omega}_{i}^{2}(M-\Delta M) \tilde{\phi}_{i}=0 ;
$$

where $K$, and $M$ are the stiffness and mass matrix, $\omega_{i}$ is the $i^{\text {th }}$ natural frequency, $\phi_{i}$ is the corresponding mode shape, and $\Delta K$ and $\Delta M$ are reduction in stiffness and mass matrices, respectively. 
Table 3. Results of IMARS.

\begin{tabular}{|c|c|c|c|c|c|c|c|}
\hline \multirow{2}{*}{ Test function } & \multicolumn{3}{|c|}{ Mean number of function evaluation } & \multicolumn{3}{|c|}{ Mean function value } & \multirow{2}{*}{$\begin{array}{c}\text { Global } \\
\text { optimum value }\end{array}$} \\
\hline & IMARS & $\begin{array}{c}\text { He and } \\
\text { Hwang [14] }\end{array}$ & $\begin{array}{l}\text { Leung and } \\
\text { Wang [41] }\end{array}$ & IMARS & $\begin{array}{c}\text { He and } \\
\text { Hwang [14] }\end{array}$ & $\begin{array}{l}\text { Leung and } \\
\text { Wang [41] }\end{array}$ & \\
\hline$f_{1}$ & 45,7762 & 49,660 & 302,166 & -12596.48661 & -12596.468 & -12596.4537 & -12596.5 \\
\hline$f_{2}$ & 55,719 & 65,922 & 224,710 & 0 & 0 & 0 & 0 \\
\hline$f_{3}$ & 21,845 & 15,406 & 112,652 & 0.0011445 & 0.00473 & 0.00630 & 0 \\
\hline$f_{4}$ & 8758 & Not tested & 245,930 & -78.33233 & Not tested & -78.3000296 & -78.33236 \\
\hline
\end{tabular}

Let $\boldsymbol{\alpha}$ be the vector of stiffness damaged factor $\boldsymbol{\alpha}=\boldsymbol{\alpha}_{\boldsymbol{i}}$, $i=1: N E$, and let $\boldsymbol{\beta}$ be the vector of mass damaged factor $\boldsymbol{\beta}=\boldsymbol{\beta}_{i}, i=1: N E$. Where $N E$ is number of element.

If damage extent of the $i^{\text {th }}$ element is $d(0 \leq d \leq 1)$, the stiffness damage factor $\boldsymbol{\alpha}_{i}$ or density damage factor $\boldsymbol{\beta}_{i}$ is equal to $1-d$.

Consider $\gamma$ a vector of damaged factors grouping $\boldsymbol{\alpha}$ and $\boldsymbol{\beta}$ as

$$
\gamma=\left\{\begin{array}{c}
\boldsymbol{\alpha} \\
\boldsymbol{\beta}
\end{array}\right\}=\left\{\begin{array}{c}
\boldsymbol{\alpha}_{i} \\
\boldsymbol{\beta}_{i}
\end{array}\right\}, i=1: N E
$$

The objective function $\Psi$ (eq. (5)) can be written according to $\gamma$ as

$$
\Psi(\{\gamma\})=W_{\omega} J_{\omega}(\{\gamma\})+W_{M A C} J_{M A C}(\{\gamma\}) .
$$

Thus, the optimization problem presented here can be defined as $\min \Psi(\{\gamma\})$ subjected to

$$
\begin{gathered}
J_{\omega}(\{\gamma\})<J_{\omega}(\gamma=1) \\
\text { and } J_{M A C}(\{\gamma\})<J_{M A C}(\gamma=1) \\
0 \leq \gamma_{i} \leq 1
\end{gathered}
$$

\subsection{Detection Phase}

In model updating, the non-uniqueness of updated models is an important concern in damage identification as well as model updating. In this work, this particularity is exploited to develop a new damage detection method based on analytical modal data obtained from several runs of the proposed algorithm.

The basic form of an eigenvalue problem is

$$
[A-\lambda I] x=0
$$

where $A=$ square matrix, $\lambda=$ eigenvalues, $I=$ identity matrix, and $x=$ eigenvectors.

In structural analysis, the representations of stiffness and mass matrices in eigenequation result in the physical representations of natural frequencies and mode shapes. Therefore, the eigenequation is written in terms of $K, \omega$, and $M$ as shown in Eq. (6) with $\omega_{i}^{2}=\lambda$.

$$
[K-\lambda M] \phi_{i}=0 .
$$

Multiplying $K$ and $M$ in Eq. (11) by a factor $\varphi>0$, gives

$$
\left((\varphi K) \phi_{i}-\lambda(\varphi M) \phi_{i}=0 .\right.
$$

One can see from this equation that mode shapes are not affected by the change in $K$ and $M$. The general mathematical eigenvalue problem is given by solving the equation

$$
\operatorname{det}((\varphi K)-\lambda(\varphi M))=|(\varphi K)-\lambda(\varphi M)|=0 .
$$

This equation is equivalent to

$$
|(K)-\lambda(M)|=0 .
$$

It is obvious from this equation that the factor $\varphi$ do not affect the eigenvalues of structural system.

When the model updating process is running several times to obtain updated parameter values $(\gamma)$, and when no restriction is imposed on the search interval, one can observe, when convergence occurs, that the values of $\gamma_{i}, i=1: N_{c}$ for each run are not the same ( $N_{c}$ is the number of convergent run), but $\gamma_{i}$ have the same variations. Despite these variations, the obtained natural frequencies and mode shapes (for updated model) for each convergent run are very close. By plotting these variations (matrix of $\gamma_{i}$ ) and by the judgment of analyst, one can, in an easy way, detect graphically the positions and the number of parameters which are affected by errors. (see simulated examples).

\subsection{Quantification Phase}

The second phase after the damage detection is the quantification phase. Here, a new simple method is proposed. First, when the number of damages is found, the parameters which are not affected by errors $\left(\left\{\alpha_{i}, \beta_{i}\right\}^{T}\right)$ are grouped together. The evaluation of the damage in affected parameters is then done as follows:

Let the number of affected parameters $N_{d}$ be given. The number of non-affected parameters $N_{n d}$ can be calculated from number of parameters $N_{p}$

$$
N_{n d}=\text { length }\left(\gamma_{i}\right)-N_{d}=N_{p}-N_{d} .
$$

The grouping of the non-affected parameters to obtain a single parameter vector $P_{v}$ is given as

$$
p_{v}=\sum_{i=N_{n d}} \gamma(i) / N_{n d}
$$

$p_{v}$ represents the reference vector to quantify the damage in affected parameters.

The final vector $\gamma_{f}$ grouping all parameters (affected and nonaffected) is given by the following formula

$$
\gamma_{f}=\sum_{i=1}^{N_{p}}\left(\gamma_{i} / p_{v}\right) / N_{c} .
$$




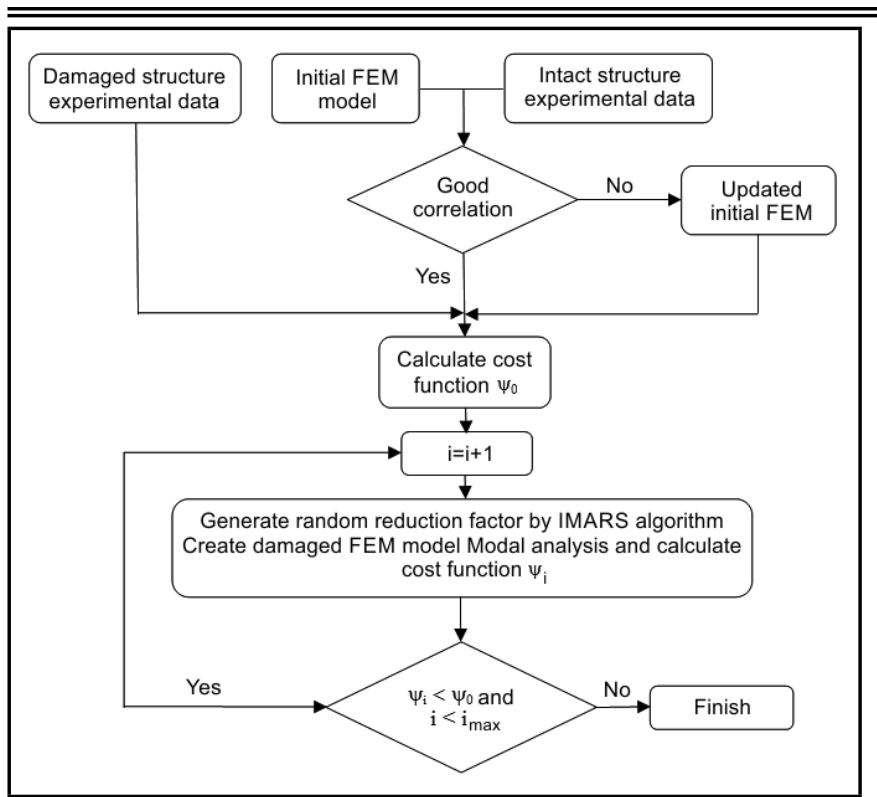

Figure 1. Flowchart of damage detection procedure using IMARS.

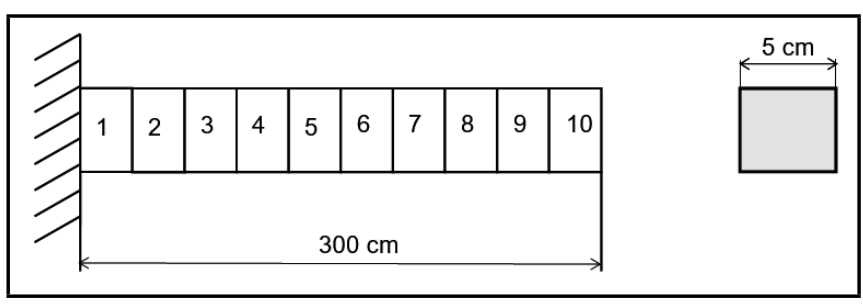

Figure 2. Cantilever beam model for damaged detection.

Figure 1 summarizes the diverse steps of the proposed algorithm including different phases of damage detection procedure.

\section{SIMULATED SYSTEM OF BEAM MODEL}

The first problem to verify the proposed algorithm in model updating for damage detection is a cantilever beam as shown in Fig. 2. The model has undamped ten elements of one-meter length. This model is characterized by 20 parameters to be updated because each of 10 elements has the stiffness and the mass to update. The beam of three-meter length has a square section of $25 \cdot 10^{-4} \mathrm{~m}^{2}$, and its material is characterized by the Young's modulus of $2.1 \cdot 10^{11} \mathrm{~N} / \mathrm{m}^{2}$, and the density of $7800 \mathrm{~kg} / \mathrm{m}^{3}$.

For this example, the simulated experimental (real) data consists of seven natural frequencies and seven mode shapes.

The initial $p$-values are set to 1 , and the updated $p$-values are generated randomly between 0 and 1 , where the value equal to 0 corresponds to no damage change and to no change of the parameter. For this case, four scenarios of damage were examined. The target damages in stiffness (flexural stiffness $E_{i} I_{i}$ ) and mass (density $\rho_{i}$ ) are summarized in Table 4 and Table 6a. The first seven natural frequencies of the analytical (initial) and real (target) models and the diagonal values of the MAC are shown in Table 5. In the last multiple damage (scenario 4), small damages and noisy source affecting vibration data were considered (Table 6a). This scenario is presented to test the effect of noisy data on damage detection procedure especially for small damages. To validate the accuracy of obtained re-
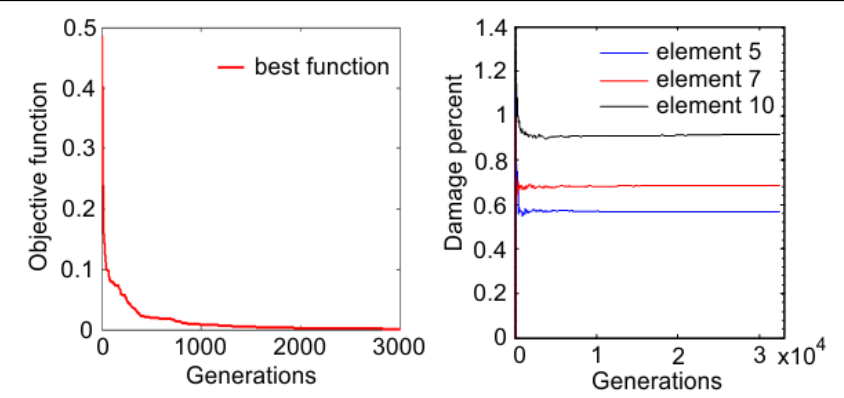

(a)

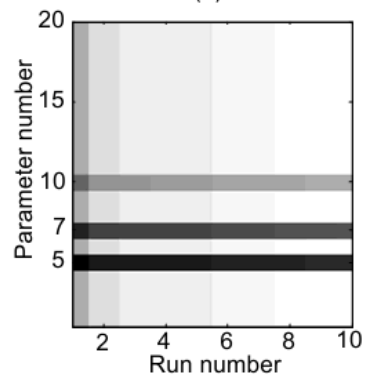

(c)

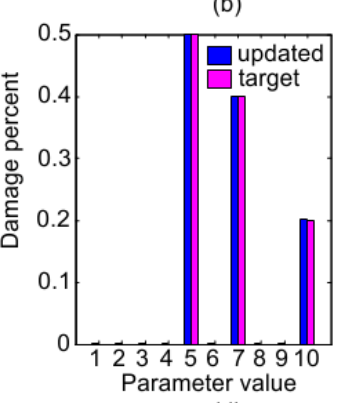

(d)
Figure 3. Results of the beam damage identification problem for damage scenario 1. (a) Convergence history of the best objective function; (b) Convergence history of the damaged elements term for the best solution; (c) Graphical stiffness damage detection; (d) Stiffness damage percent for each element.

sults, the updated parameters must match very well the target damaged parameters for the four scenarios.

The updating process starts by evaluating the objective function of initial FE model. To have compatible contribution to the objective function, the values of weighting factors $W_{\omega}$ and $W_{M A C}$ have been selected and set after several runs to 10 and 1 , respectively, depending on the effect of each part of the objective function on the convergence of updating process. The values of IMARS parameters are the same as taken in section (2.3), and are selected at the beginning of the optimization process.

By considering the stochastic process, the IMARS algorithm has been run 15 times independently. The first ten best results of model updating are then taken and applied for damage detection procedure. In general, when using experimental vibration data for real structures, the initial finite element model of undamaged structure must be updated to match experimental data. In simulated examples presented here, it is assumed that the undamaged system can be accurately represented by the initial finite element model, and this model could be used in damage detection process.

\subsection{Damage Detection Results}

The convergence history of the best objective function for the first three scenarios is shown in Figs. 3a, 4a, and 5a respectively. The convergence speed is very high even though the number of iteration is less than 1000 iterations for each case. Figures $3 \mathrm{~b}, 4 \mathrm{~b}$, and $5 \mathrm{~b}$ illustrate the convergence history of the damaged elements term for the best solution. These figures indicate that the proposed algorithm could find the global solutions with high precision for all scenarios.

The graphical detection of stiffness and density damages is given in Figs. 3c, 4c and 5d for stiffness, and Fig. 5e for density. From these figures, one can detect the location of damaged element for each scenario. As a result, the target damages 
Table 4. Target parameters for simulated beam model.

\begin{tabular}{|c|c|c|c|c|c|c|c|c|}
\hline \multirow{2}{*}{$\begin{array}{c}\text { Element } \\
\text { number }\end{array}$} & \multicolumn{2}{|c|}{$\begin{array}{c}\text { Scenario 1 } \\
\text { Parameters and damage }\end{array}$} & \multicolumn{2}{c|}{$\begin{array}{c}\text { Scenario 2 } \\
\text { Parameters and damage }\end{array}$} & \multicolumn{2}{c|}{$\begin{array}{c}\text { Scenario 3 } \\
\text { Parameters and damage }\end{array}$} & \multicolumn{2}{c|}{$\begin{array}{c}\text { Scenario } 4 \\
\text { Parameters an damage }\end{array}$} \\
\cline { 2 - 8 } & Stiffness & Mass & Stiffness & Mass & Stiffness & Mass & Stiffness & Mass \\
\hline 1 & 1 & 1 & 1 & $0.7(30 \%)$ & 1 & 1 & 1 & 1 \\
2 & 1 & 1 & 1 & 1 & $0.4(60 \%)$ & 1 & $0.4(60 \%)$ & 1 \\
3 & 1 & 1 & 1 & 1 & 1 & 1 & 1 & 1 \\
4 & 1 & 1 & 1 & $0.5(50 \%)$ & 1 & 1 & 1 & 1 \\
5 & $0.5(50 \%)$ & 1 & 1 & 1 & $0.6(40 \%)$ & $0.5(50 \%)$ & $0.85(15 \%)$ & 1 \\
6 & 1 & 1 & 1 & 1 & 1 & 1 & 1 & 1 \\
7 & $0.6(40 \%)$ & 1 & 1 & 1 & 1 & $0.4(60 \%)$ & $0.9(10 \%)$ & 1 \\
8 & 1 & 1 & 1 & $0.4(0.6 \%)$ & 1 & 1 & 1 & 1 \\
9 & 1 & 1 & 1 & 1 & 1 & 1 & 1 & 1 \\
10 & $0.8(20 \%)$ & 1 & 1 & 1 & 1 & 1 & 1 & 1 \\
\hline
\end{tabular}

Table 5. Modal properties of simulated beam model (Case 1, 2, 3, and 4).

\begin{tabular}{|c|c|c|c|c|c|c|c|c|c|c|c|c|c|}
\hline \multirow[b]{2}{*}{$\begin{array}{l}\text { Mode } \\
\text { number }\end{array}$} & \multirow[b]{2}{*}{$\begin{array}{c}\text { Numerical } \\
\text { frequencies } \\
(\mathrm{Hz})\end{array}$} & \multicolumn{3}{|c|}{ Case 1} & \multicolumn{3}{|c|}{ Case 2} & \multicolumn{3}{|c|}{ Case 3} & \multicolumn{3}{|c|}{ Case 4} \\
\hline & & $\begin{array}{c}\text { Target } \\
\text { frequencies } \\
(\mathrm{Hz})\end{array}$ & $\begin{array}{l}\text { Diagonal } \\
\text { of MAC }\end{array}$ & $\begin{array}{c}\text { Frequency } \\
\text { Error \% }\end{array}$ & \begin{tabular}{|c|} 
Target \\
frequencies \\
$(\mathrm{Hz})$
\end{tabular} & $\begin{array}{l}\text { Diagonal } \\
\text { of MAC }\end{array}$ & $\begin{array}{c}\text { Frequency } \\
\text { Error } \%\end{array}$ & $\begin{array}{c}\text { Target } \\
\text { frequencies } \\
(\mathrm{Hz})\end{array}$ & $\begin{array}{l}\text { Diagonal } \\
\text { of MAC }\end{array}$ & $\begin{array}{c}\text { Frequency } \\
\text { Error } \%\end{array}$ & \begin{tabular}{|c|} 
Target \\
frequencies \\
$(\mathrm{Hz})$
\end{tabular} & $\begin{array}{l}\text { Diagonal } \\
\text { of MAC }\end{array}$ & $\begin{array}{c}\text { Frequency } \\
\text { Error \% }\end{array}$ \\
\hline 1 & 4.494 & 4.657 & 1.000 & 3.497 & 4.939 & 1.000 & 5.709 & 4.081 & 1.000 & 12.353 & 3.946 & 0.999 & 15.267 \\
\hline 2 & 25.984 & 29.183 & 0.999 & 10.963 & 30.499 & 0.998 & 4.312 & 29.470 & 0.988 & 0.980 & 27.826 & 0.999 & 4.649 \\
\hline 3 & 75.990 & 81.733 & 0.996 & 7.026 & 90.060 & 0.987 & 9.247 & 84.927 & 0.993 & 3.908 & 79.728 & 0.999 & 2.453 \\
\hline 4 & 150.621 & 160.275 & 0.992 & 6.024 & 170.426 & 0.979 & 5.956 & 154.479 & 0.980 & 3.616 & 150.908 & 0.988 & 5.844 \\
\hline 5 & 245.888 & 265.361 & 0.982 & 7.338 & 281.268 & 0.983 & 5.655 & 258.570 & 0.945 & 2.559 & 246.343 & 0.981 & 7.166 \\
\hline 6 & 370.964 & 397.541 & 0.983 & 6.685 & 427.788 & 0.957 & 7.070 & 404.511 & 0.895 & 1.753 & 370.64 & 0.978 & 6.766 \\
\hline 7 & 520.430 & 557.770 & 0.992 & 6.694 & 606.238 & 0.963 & 7.995 & 546.857 & 0.947 & 1.956 & 528.402 & 0.971 & 5.265 \\
\hline
\end{tabular}

Table 6a. Values of noisy data for scenario 4.

\begin{tabular}{|c|c|c|}
\hline Case number & $\begin{array}{c}\text { Deviation in measured } \\
\text { natural frequencies }\end{array}$ & $\begin{array}{c}\text { Deviation in measured } \\
\text { mode shapes }\end{array}$ \\
\hline Case 1 & $0 \%$ & $0 \%$ \\
\hline Case 2 & $2 \%$ & $5 \%$ \\
\hline Case 3 & $2 \%$ & $7 \%$ \\
\hline
\end{tabular}

for each scenario (Table 4) have been detected and the obtained results match very well the target damages.

The predicted stiffness and density damage factors of all elements are almost the same with the true values, and only elements 5, 7, and 10 are damaged.

The searched results of stiffness and density damage factor for all elements are shown in Figs. 3d, 4d, 5d, and 5f. The positions and extents of damage occurrence are reasonably detected for each scenario. However, compared to conventional approaches, the present algorithm is still more effective in detecting multi-damage occurrence with reasonable high precision under sparse data.

The searched results of stiffness damage factor of each element for different cases of scenario 4 are listed in Table $6 \mathrm{~b}$ and figs. 6 a to 6 e. For case 1 and case 2, the effect of multi-run process on detecting small size damages in presence of large damages and noisy data is illustrated in Figs. 6a and 6b. One can see that the algorithm has perfectly detected the small damages (parameter 3 and 5) among large damages (parameter 2) for each run, and these damages have the same variation that separate them than noisy results. Figures. $6 \mathrm{c}$ and $6 \mathrm{~d}$ illustrate the values of damage factor that are quantified with good precision. The maximum error of stiffness damage factor is only $3.81 \%$ for case 1 and $7.11 \%$ for case 2 (Table 6b). It shows that even if the problem is multi-damage occurrence and the

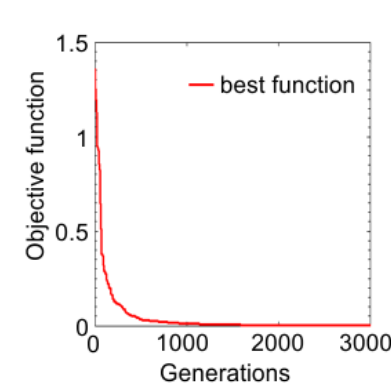

(a)

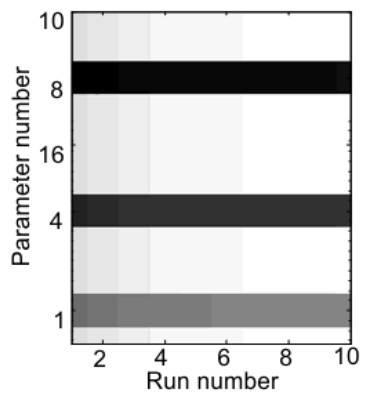

(c)

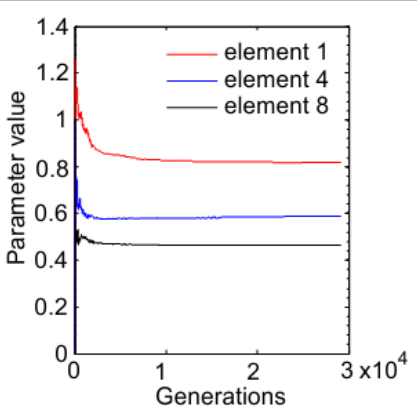

(b)

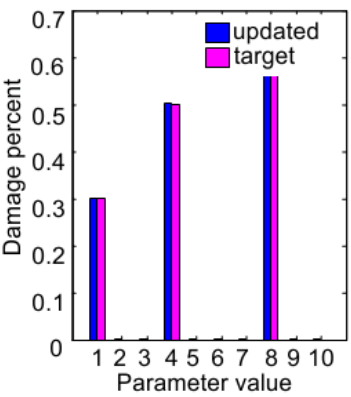

(d)
Figure 4. Results of the beam damage identification problem for damage scenario 2. (a) Convergence history of the best objective function; (b) Convergence history of the damaged elements term for the best solution; (c) Graphical density damage detection; (d) Density damage percent for each element.

damage extents are small, the searched results agree with the exact values very well for the objective function in case 1 and 2. If noise is increased in mode shapes, the maximum error is increased to $11.97 \%$ for case 3 , and in addition to the three really damaged elements, one unexpected element is predicted to be damaged in case 3 . Hence, the results stay acceptable 
Table 6b. Stiffness damage factors for beam structure (scenario 4).

\begin{tabular}{|c|c|c|c|c|c|c|c|c|c|}
\hline $\begin{array}{c}\text { Parameter } \\
\text { number }\end{array}$ & Target & $\begin{array}{c}\text { Parameter } \\
\text { value without } \\
\text { noisy (case 1) }\end{array}$ & Error & $\begin{array}{c}\text { Parameter } \\
\text { value with } \\
\text { noisy (case 2) }\end{array}$ & Error & $\begin{array}{c}\text { Parameter } \\
\text { value with } \\
\text { noisy (case 3) }\end{array}$ & Error & $\begin{array}{c}\text { Parameter } \\
\text { value with } \\
\text { noisy (case 4) }\end{array}$ & $\begin{array}{c}\text { Error } \\
\text { (cas }\end{array}$ \\
\hline 1 & 1 & 0.962 & $\mathbf{3 . 8 1 \%}$ & 0.929 & $\mathbf{7 . 1 1 \%}$ & 1.0000 & 0 & 0.8891 & $11.09 \%$ \\
3 & 0.4 & 0.412 & $-2.99 \%$ & 0.424 & $-6.08 \%$ & 0.4401 & $10.02 \%$ & 0.3571 & $10.73 \%$ \\
4 & 1 & 0.994 & $0.56 \%$ & 0.993 & $0.65 \%$ & 0.8802 & $\mathbf{1 1 . 9 7 \%}$ & 1.0000 & $0 \%$ \\
5 & 0.85 & 0.9927 & $-0.73 \%$ & 0.999 & $0.12 \%$ & 0.9563 & $4.37 \%$ & 0.7818 & $21.82 \%$ \\
6 & 1 & 0.999 & $-0.59 \%$ & 0.850 & $0.05 \%$ & 0.8992 & $5.79 \%$ & 0.7304 & $14.07 \%$ \\
7 & 0.9 & 0.911 & $-1.18 \%$ & 0.909 & $-0.96 \%$ & 0.8992 & $0.08 \%$ & 0.9306 & $3.39 \%$ \\
8 & 1 & 0.996 & $0.36 \%$ & 0.9987 & $-0.13 \%$ & 0.9449 & $5.51 \%$ & 0.7791 & $\mathbf{2 2 . 0 9 \%}$ \\
9 & 1 & 0.9915 & $-0.85 \%$ & 0.9936 & $-0.64 \%$ & 0.9876 & $1.23 \%$ & 0.9017 & $9.82 \%$ \\
10 & 1 & 0.9959 & $-0.41 \%$ & 0.9941 & $-0.59 \%$ & 0.9306 & $6.93 \$$ & 0.9603 & $3.96 \%$ \\
\hline
\end{tabular}

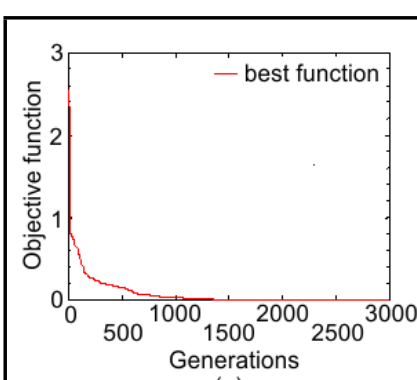

(a)

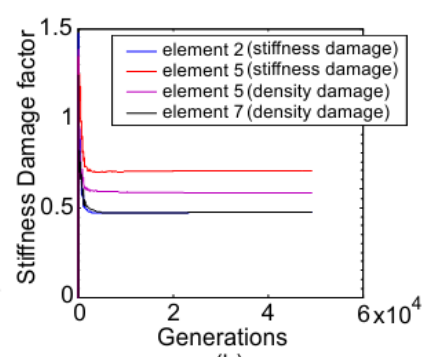

(b)

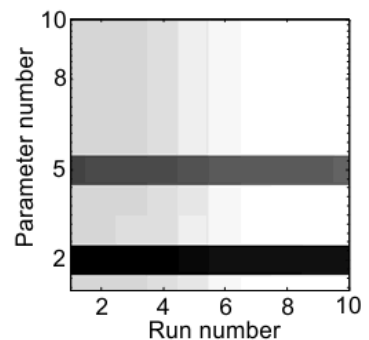

(c)

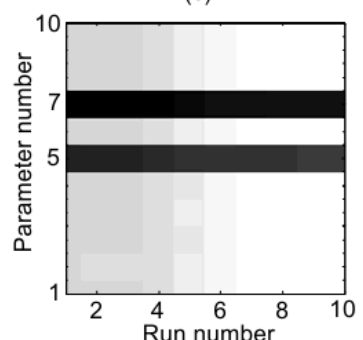

(e)

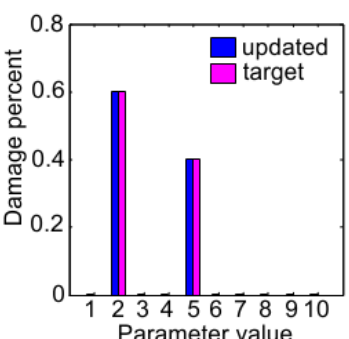

(d)

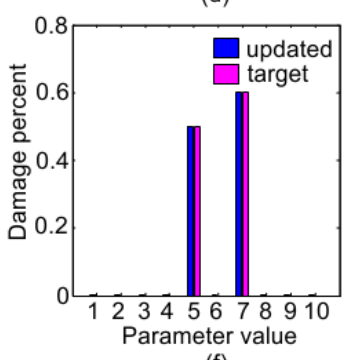

(f)

Figure 5. Results of the beam damage identification problem for damage scenario 3. (a) Convergence history of the best objective function; (b) Convergence history of the damaged elements term for the best solution; (c) Graphical stiffness damage detection; (d) Density damage percent for each element; (e) Graphical stiffness damage detection; (f) Density damage percent for each element.

for simulated examples when the noise increases. When using experimental vibration data for real structures, the initial finite element model of undamaged structures must be updated to match experimental data, which can improve the correlation between target and updated results and reduce considerably the effect of noise (see section 6).

\section{BOWSTRING TRUSS EXAMPLE}

The presented damage detection algorithm was applied also to a truss structure as shown in Fig. $7 .^{21}$ The large size structure is modelled numerically using the finite element method with basic structural elements, i.e. bar elements. The finite

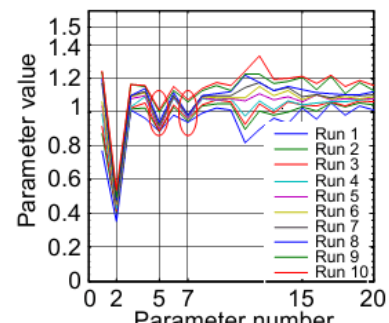

(a)

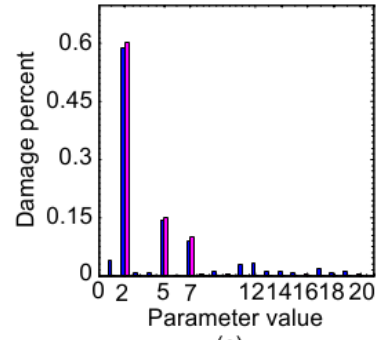

(c)

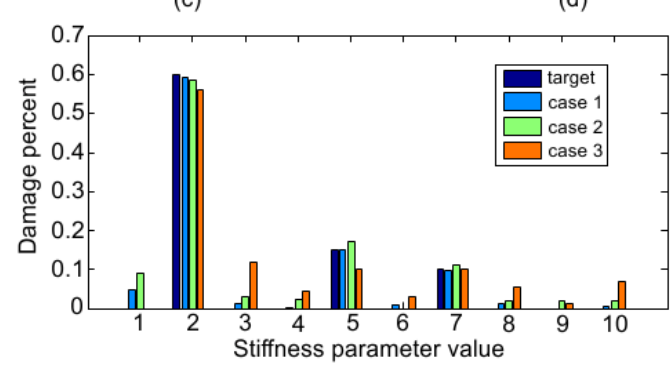

(e)

(b)

(d)
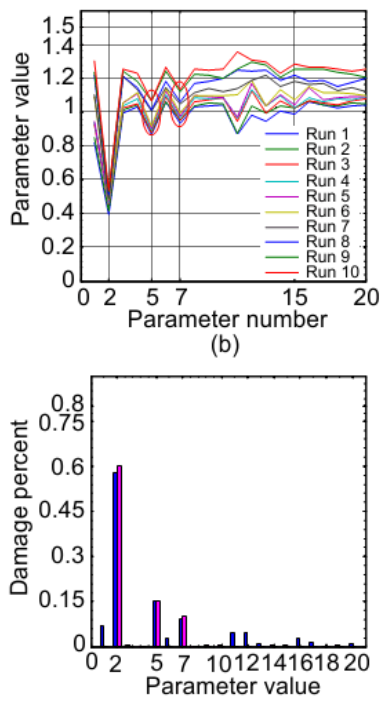

Figure 6. Results of the beam damage identification problem for damage scenario 4. (a) Graphical stiffness damage detection (case 1); (b) Graphical stiffness damage detection (case 2); (c) Stiffness damage percent for each element (case 1); (d) Stiffness damage percent for each element (case 2); (e) comparison of stiffness damage percent for each element for the four cases.

element model of the structure consists of 25 elements and 21 DOFs. Truss elements are made from steel material with Young's modulus of $20 \mathrm{MPa}$, and cross-sectional areas are given in Table 7. Kinematics degrees of freedom of this truss model are shown in Fig. 8.

The unknown parameters have axial rigidity of elements, $E A$ and density $\rho$, where $A$ is the cross-section area of truss element and $E$ is the Young's modulus. Several damage cases are considered to investigate the influence of location, severity, and number of damaged elements for the results. Table 8 shows specifications of these damage cases. The first ten natural frequencies of the analytical (initial) and real (target) models and the diagonal values of the MAC are shown in Tables 9a 


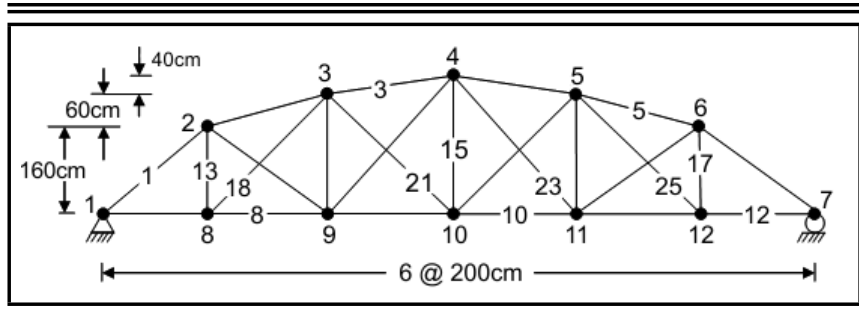

Figure 7. Geometry of truss model

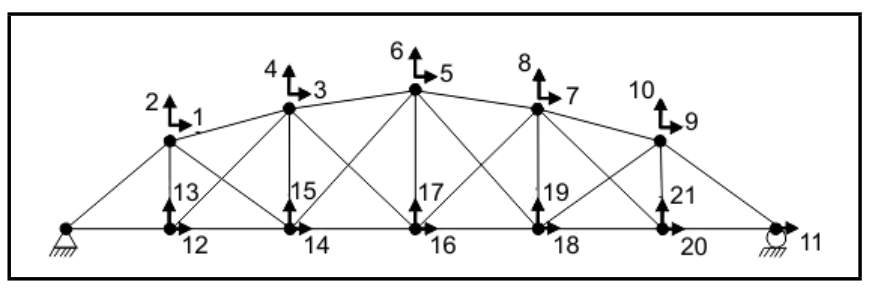

Figure 8. Degrees of freedom of truss model.

Table 7. Cross-sectional area of truss members.

\begin{tabular}{|c|c|}
\hline Member & Area $\left(\mathrm{cm}^{2}\right)$ \\
\hline $1-6$ & 18 \\
\hline $7-12$ & 15 \\
\hline $13-17$ & 10 \\
\hline $18-25$ & 12 \\
\hline
\end{tabular}

and $9 \mathrm{~b}$. The proposed algorithm works well in presence of restricted data (few frequencies and mode shapes). For this example, it is assumed that the undamaged system can be accurately represented by the initial finite element model, and this model could be used in damage detection process.

Figures. 9-16 show results of the proposed damage detection method.

The graphical detection of stiffness and density damage parameters for each scenario are shown in Figs. 9a, 10a, 11a, 12a, 13a, 14a, 15a, 15c, 16a, and 16c. These figures show that all runs for each scenario are able to detect the same damages for each scenario, and the target damages for each scenario (Table 8) have been detected. For example, in Figs. 16a and 16c, one can see that all runs converge to the same parameters (4, 8,12 , and 24 for stiffness and 8, 16, and 19 for mass).

On the other hand, for the damage quantification phase, Equations. (15), (16), and (17) are used to evaluate the quantity of damage for each parameter. This evaluation has led to very good results shown in Figs. 9b, 10b, 11b, 12b, 13b, 14b, 15b, $15 \mathrm{~d}, 16 \mathrm{~b}$, and $16 \mathrm{~d}$. For example, for the last scenario, the proposed algorithm is capable of detecting the same percent damage location (Figs. 16b and 16d), and also quantify the severity using incomplete measured modal data. Moreover, the proposed damage procedure has been able to obtain very acceptable results for all studied cases approving the robustness of the proposed method.

\section{EXPERIMENTAL VALIDATION}

In the preceding two sections, the damage identification method was demonstrated through extensive numerical simulation studies with realistic levels of damage in beam and truss. However, it is still useful to examine the empirical performance of the proposed method using measured data from experimental study. Therefore, in this section, the performance

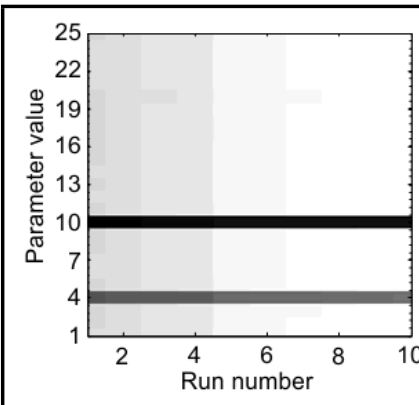

(a)

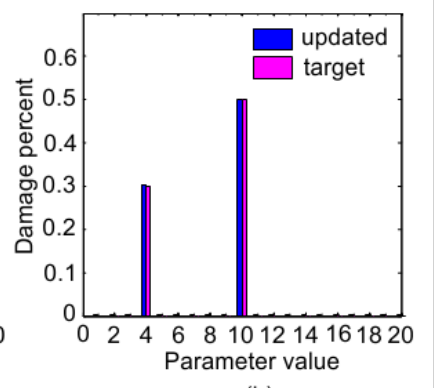

(b)

Figure 9. Results of the truss damage identification problem for damage scenario 1. (a) Graphical stiffness damage detection; (b) Stiffness damage percent for each element.

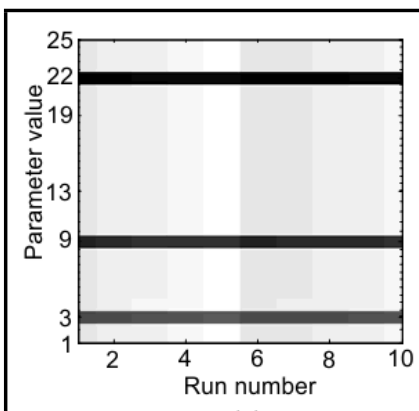

(a)

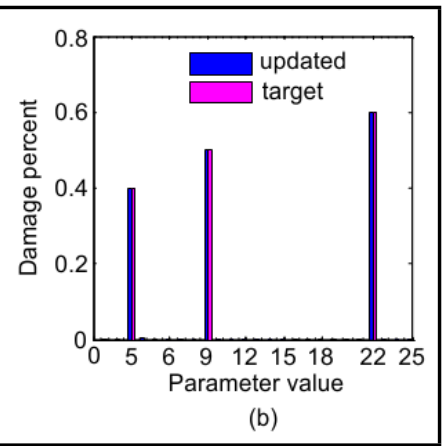

Figure 10. Results of the truss damage identification problem for damage scenario 2. (a) Graphical stiffness damage detection; (b) Stiffness damage percent for each element.

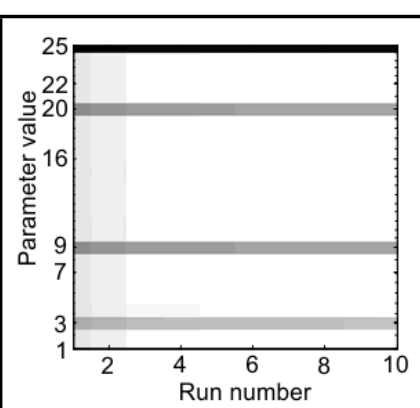

(a)

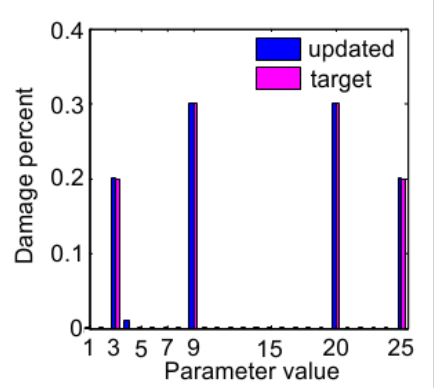

(b)
Figure 11. Results of the truss damage identification problem for damage scenario 3. (a) Graphical stiffness damage detection; (b) Stiffness damage percent for each element.

of the damage detection procedure is validated through experimental modal testing carrying out on a cantilever duralumin beam, having length, $L=469 \mathrm{~mm}$, depth, $D=20.4 \mathrm{~mm}$, and thickness, $t=3.98 \mathrm{~mm}$, in the laboratory. The material is characterized by a Young's modulus of $73.1 \cdot 10^{9} \mathrm{~N} / \mathrm{m}^{2}$ and density of $2780 \mathrm{~kg} / \mathrm{m}^{3}$. The modelled structure is divided into 15 equidistant elements of $30 \mathrm{~mm}$ length and the $16^{\text {th }}$ element of $19 \mathrm{~mm}$ (i.e. 17 nodes).

The procedure consisted of first measuring the modal parameters, grouping measured FRFs, natural frequencies, damping ratios and mode shapes, of the undamaged beam to be used for model updating, and then incrementally inducing new damage states and measuring the modal properties associated with each damage state. Damage was introduced in the form of an open crack (half width of the beam) perpendicular to the longitudinal axis on the top surface of the beam by a saw 
Table 8. Percentage of stiffness and mass reduction of elements.

\begin{tabular}{|c|c|c|c|c|c|c|}
\hline Case number & \multicolumn{6}{|c|}{ Element number and percent of damage } \\
\hline \multirow{2}{*}{1} & \multirow[t]{2}{*}{ Element number damage } & 40 & 10 & - & - & - \\
\hline & & $30 \%(\mathrm{~K})$ & $50 \%(\mathrm{~K})$ & - & - & - \\
\hline \multirow{2}{*}{2} & \multirow[t]{2}{*}{ Element number damage } & 3 & 9 & 22 & - & - \\
\hline & & $40 \%(\mathrm{~K})$ & $50 \%(\mathrm{~K})$ & $60 \%(\mathrm{~K})$ & - & - \\
\hline \multirow{2}{*}{3} & \multirow[t]{2}{*}{ Element number damage } & 3 & 9 & 20 & 25 & - \\
\hline & & $20 \%(\mathrm{~K})$ & $30 \%(\mathrm{~K})$ & $30 \%(\mathrm{~K})$ & $20 \%(\mathrm{~K})$ & - \\
\hline \multirow{2}{*}{4} & \multirow{2}{*}{ Element number damage } & 5 & 10 & 13 & 20 & 24 \\
\hline & & $40 \%(\mathrm{~K})$ & $40 \%(\mathrm{~K})$ & $50 \%(\mathrm{~K})$ & $40 \%(\mathrm{~K})$ & $30 \%(\mathrm{~K})$ \\
\hline \multirow{2}{*}{5} & \multirow[t]{2}{*}{ Element number damage } & 5 & 11 & 17 & - & - \\
\hline & & $20 \%(\mathrm{M})$ & $30 \%(\mathrm{M})$ & $30 \%(\mathrm{M})$ & - & - \\
\hline \multirow{2}{*}{6} & \multirow[t]{2}{*}{ Element number damage } & 3 & 14 & 19 & 23 & - \\
\hline & & $20 \%(\mathrm{M})$ & $30 \%(\mathrm{M})$ & $30 \%(\mathrm{M})$ & $30 \%(\mathrm{M})$ & - \\
\hline \multirow{4}{*}{7} & \multirow[t]{4}{*}{ Element number damage } & 4 & 8 & 12 & 24 & - \\
\hline & & $30 \%(\mathrm{~K})$ & $40 \%(\mathrm{~K})$ & $30 \%(\mathrm{~K})$ & $40 \%(\mathrm{~K})$ & - \\
\hline & & 8 & 16 & 19 & - & - \\
\hline & & $30 \%(\mathrm{M})$ & $30 \%(\mathrm{M})$ & $40 \%(\mathrm{M})$ & - & - \\
\hline \multirow{4}{*}{8} & \multirow[t]{4}{*}{ Element number damage } & 4 & 12 & 19 & - & - \\
\hline & & $30 \%(\mathrm{~K})$ & $30 \%(\mathrm{~K})$ & $30 \%(\mathrm{~K})$ & - & - \\
\hline & & 5 & 17 & 22 & - & - \\
\hline & & $30 \%(\mathrm{M})$ & $30 \%(\mathrm{M})$ & $30 \%(\mathrm{M})$ & - & - \\
\hline
\end{tabular}

Table 9a. Modal properties of simulated truss model (Case 1, 2, 3, and 4).

\begin{tabular}{|c|c|c|c|c|c|c|c|c|c|}
\cline { 3 - 11 } \multicolumn{2}{c|}{} & \multicolumn{2}{c|}{ Case 1 } & \multicolumn{2}{c|}{ Case 2 } & \multicolumn{2}{c|}{ Case 3 } & \multicolumn{2}{c|}{ Case 4 } \\
\hline $\begin{array}{c}\text { Mode } \\
\mathrm{N}\end{array}$ & $\begin{array}{c}\text { Numerical } \\
\text { frequencies } \\
(\mathrm{Hz})\end{array}$ & $\begin{array}{c}\text { Target } \\
\text { frequencies } \\
(\mathrm{Hz})\end{array}$ & $\begin{array}{c}\text { Diagonal } \\
\text { of MAC }\end{array}$ & $\begin{array}{c}\text { Target } \\
\text { frequencies } \\
(\mathrm{Hz})\end{array}$ & $\begin{array}{c}\text { Diagonal } \\
\text { of MAC }\end{array}$ & $\begin{array}{c}\text { Target } \\
\text { frequencies } \\
(\mathrm{Hz})\end{array}$ & $\begin{array}{c}\text { Diagonal } \\
\text { of MAC }\end{array}$ & $\begin{array}{c}\text { Target } \\
\text { frequencies } \\
(\mathrm{Hz})\end{array}$ & $\begin{array}{c}\text { Diagonal } \\
\text { of MAC }\end{array}$ \\
\hline 1 & 28.609 & 27.7052 & 0.9986 & 26.500 & 0.992 & 27.6478 & 0.9996 & 27.347 & 0.999 \\
\hline 2 & 71.875 & 70.1250 & 0.9962 & 67.948 & 0.992 & 71.2632 & 0.9986 & 70.463 & 0.999 \\
\hline 3 & 95.542 & 95.1366 & 0.9992 & 86.390 & 0.996 & 89.7488 & 0.9952 & 93.149 & 0.996 \\
\hline 4 & 179.086 & 178.3859 & 0.9851 & 174.819 & 0.987 & 175.0634 & 0.9871 & 168.937 & 0.995 \\
\hline 5 & 218.441 & 199.4983 & 0.9598 & 217.241 & 0.995 & 213.0200 & 0.9871 & 198.104 & 0.972 \\
\hline 6 & 282.605 & 278.9747 & 0.9853 & 271.086 & 0.934 & 270.5828 & 0.9399 & 260.913 & 0.964 \\
\hline 7 & 347.316 & 346.3690 & 0.9960 & 333.311 & 0.796 & 323.3932 & 0.6702 & 324.349 & 0.427 \\
\hline 8 & 367.251 & 367.1545 & 0.9991 & 349.340 & 0.110 & 358.4620 & 0.6363 & 351.879 & 0.401 \\
\hline 9 & 391.803 & 387.4713 & 0.9709 & 365.939 & 0.007 & 366.3543 & 0.0028 & 388.124 & 0.063 \\
\hline 10 & 396.560 & 396.0310 & 0.9896 & 379.388 & 0.062 & 382.4567 & 0.0010 & 389.331 & 0.029 \\
\hline
\end{tabular}

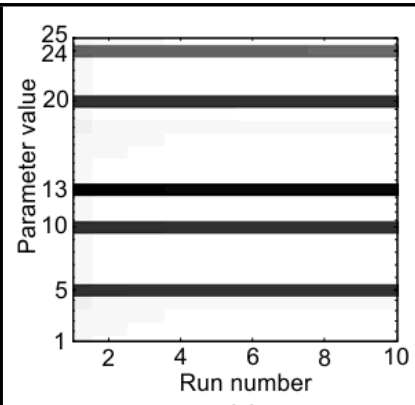

(a)

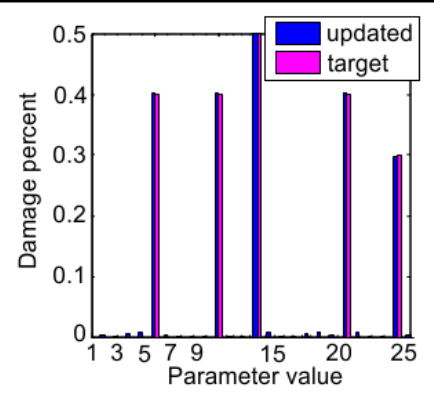

(b)

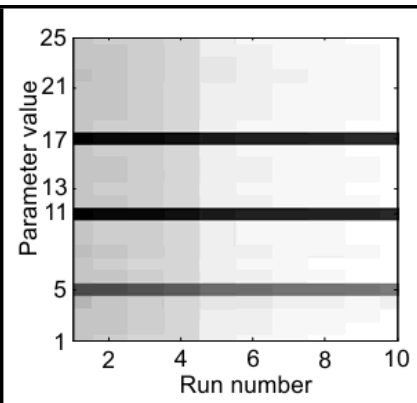

(a)

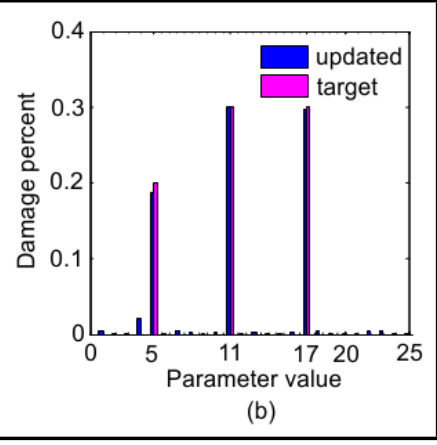

(b)

Figure 12. Results of the truss damage identification problem for damage scenario 4. (a) Graphical stiffness damage detection; (b) Stiffness damage percent for each element.

cut using a blade. The damaged beam results are presented to show the effect of cracks on measured FRFs, natural frequencies, damping ratios, and mode shapes, and then be used for damage detection. The various damage cases, crack locations are given in Fig. 17.

To examine the effect of localized single/multiple cracks on the modal frequencies, experimental modal testing was carried out using a six-channel Pulse vibration analyser using the Vold-Kalman filter.

Dynamic excitation was applied by an impact hammer (Type 8206-001) at 17 uniformly placed excitation degrees-of-

Figure 13. Results of the truss damage identification problem for damage scenario 5. (a) Graphical density damage detection; (b) Density damage percent for each element.

freedom chosen after several test and one uniaxial accelerometer (Type 4507).

In the experiment, the accelerometer was fixed at the $15^{\text {th }}$ point in the $y$-direction (Fig. 18). This position has been chosen after several tests to reduce noise in the measurements. The beam was impacted in the vertical direction at 17 points to define the mode shapes of the structure, and 17 frequency response functions (FRFs) were computed one at a time, corresponding to each impact degree of freedom (DoF). The coherence is evaluated for averaged measurements by considering five impacts at the same point to obtain the corresponding 


Table 9b. Modal properties of simulated truss model (Case 5, 6, 7, and 8).
\begin{tabular}{|c|c|c|c|c|c|c|c|}
\hline \multicolumn{2}{|c|}{ Case 5 } & \multicolumn{2}{c|}{ Case 6 } & \multicolumn{2}{c|}{ Case 7 } & \multicolumn{2}{c|}{ Case 8 } \\
\hline $\begin{array}{c}\text { Target } \\
\text { frequencies } \\
\text { (Hz) }\end{array}$ & $\begin{array}{c}\text { Diagonal } \\
\text { of MAC }\end{array}$ & $\begin{array}{c}\text { Target } \\
\text { frequencies } \\
\text { (Hz) }\end{array}$ & $\begin{array}{c}\text { Diagonal } \\
\text { of MAC }\end{array}$ & $\begin{array}{c}\text { Target } \\
\text { frequencies } \\
\text { (Hz) }\end{array}$ & $\begin{array}{c}\text { Diagonal } \\
\text { of MAC }\end{array}$ & $\begin{array}{c}\text { Target } \\
\text { frequencies } \\
\text { (Hz) }\end{array}$ & $\begin{array}{c}\text { Diagonal } \\
\text { of MAC }\end{array}$ \\
\hline 29.2734 & 1.0000 & 28.3017 & 0.9994 & 28.993 & 0.997 & 29.826 & 1.000 \\
\hline 73.2873 & 1.0000 & 72.6469 & 0.9987 & 74.854 & 0.982 & 73.264 & 0.995 \\
\hline 97.8928 & 0.9999 & 97.3847 & 0.9988 & 95.493 & 0.973 & 96.770 & 0.993 \\
\hline 183.4914 & 0.9991 & 177.3768 & 0.9959 & 166.184 & 0.894 & 171.127 & 0.947 \\
\hline 221.8583 & 0.9990 & 222.2648 & 0.9991 & 205.521 & 0.825 & 211.457 & 0.932 \\
\hline 287.5708 & 0.9985 & 283.7532 & 0.9919 & 258.029 & 0.027 & 279.440 & 0.754 \\
\hline 355.0947 & 0.9929 & 350.5885 & 0.9848 & 292.562 & 0.053 & 291.690 & 0.385 \\
\hline 369.1444 & 0.9895 & 363.8553 & 0.9646 & 321.441 & 0.091 & 346.726 & 0.000 \\
\hline 403.6270 & 0.0065 & 395.0139 & 0.9898 & 374.248 & 0.070 & 362.612 & 0.006 \\
\hline 407.9096 & 0.0003 & 399.7835 & 0.9969 & 408.892 & 0.766 & 398.821 & 0.442 \\
\hline
\end{tabular}

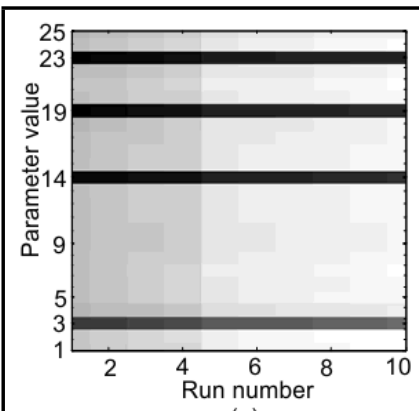

(a)

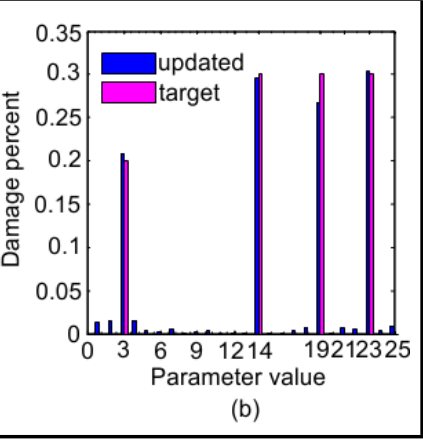

Figure 14. Results of the truss damage identification problem for damage scenario 6. (a) Graphical density damage detection; (b) Density damage percent for each element.

FRF. The structural response was measured within sampling frequency of 6400 points for a frequency range of $0-2 \mathrm{kHz}$ and in order to measure the first seven modes. The impact hammer is available with rubber, plastic, and steel tips to excite a structure in different frequency zones. After some preliminary experimentation, the impact hammer with the plastic tip was found optimal for the present investigation.

In the present study, a set of frequency response functions (FRF) obtained in the vibration analyser was exported in the desired format to Matlab, and subsequently the modal parameters were extracted using curve fitting techniques (Curve fitting Toolbox of MATLAB).

The first seven modal shapes and the first seven frequencies were extracted for the three configurations of the structure. Each data set consisted of 17 FRFs (Fig. 19). This figure indicates a high level of coherence of measurements.

The FE model of the real structure was created by taking 15 equidistant elements of $30 \mathrm{~mm}$ length and the $16^{\text {th }}$ element of $19 \mathrm{~mm}$ (i.e. 17 nodes) (Fig. 20). The first step of damage detection process eliminates the errors between the theoretical FEM and the intact structure through model tuning. In this step, the model updating algorithm (IMARS) is used to match the intact results measured experimentally to the results calculated theoretically; thus, eliminating the initial model errors. The model is characterized by 32 updating parameters, corresponding to stiffness and mass element matrices. Similarly to the previous example, the minimizing function corresponds to the objective function $\Psi$, and $p$-values are allowed to vary between 0 and 2, with 1 indicating no damage in the element parameter.

The experimental natural frequencies, and those calculated

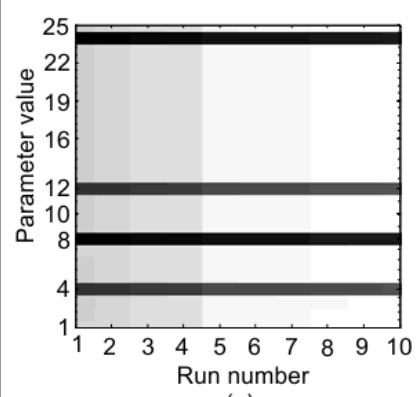

(a)

(c)

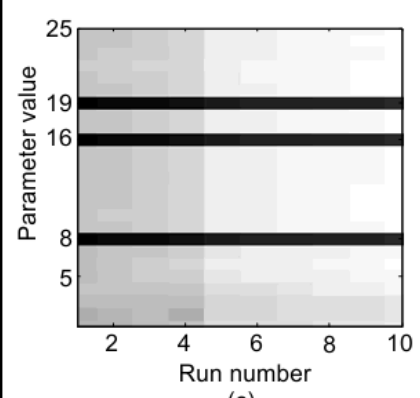

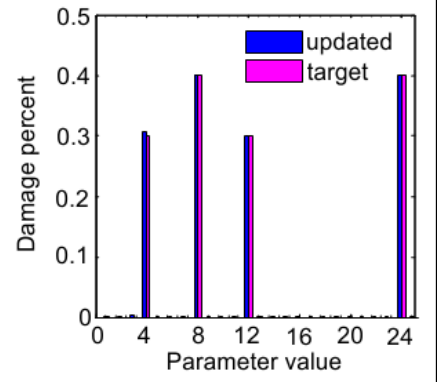

(b)

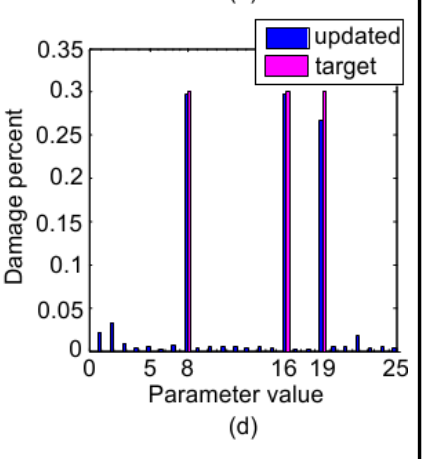

Figure 15. Results of the truss damage identification problem for damage scenario 7. (a) Graphical stiffness damage detection; (b) Stiffness damage percent for each element; (c) Graphical density damage detection; (d) Density damage percent for each element.

using the FE model, are shown in Tables 10 and 11. The mode shapes of the FE analysis and experimental results are compared using the MAC values.

The IMARS updating algorithm has been executed for the same set of parameters as in the previous numerical example. The values of weighting factors $W_{\omega}$ and $W_{M A C}$ have been set to 500 and 10, respectively, and have been selected after several test runs of the IMARS procedure. The obtained results are presented in Tables 10 .

It can clearly be seen that the IMARS has ameliorated considerably the modal properties of the initial model. The diagonal terms of the MAC are greater than 0.99 ( 0.97 before), also the relative error in frequency has been clearly ameliorated.

The next step is to match the results of a damaged structure to the update FEM from the model tuning phase. The difference between the correction factors from the tuning step and the damage detection step can be used as an indicator of the location and magnitude of damage.

A comparison between damaged and intact measured FRF for each case are shown in the Fig. 21. Effect of the single 
Table 10. Comparison of modal parameters from updated FE model and experimental measurements.

\begin{tabular}{|c|c|c|c|c|c|c|c|c|}
\hline \multirow{2}{*}{$\begin{array}{c}\text { Mode } \\
\text { number }\end{array}$} & Experimental & Damping & \multicolumn{3}{|c|}{ Initial model } & \multicolumn{3}{c|}{ Updated FE Model } \\
\cline { 5 - 9 } & frequency (Hz) & ratio & $\begin{array}{c}\text { Natural } \\
\text { frequency } \\
(\mathrm{Hz})\end{array}$ & $\begin{array}{c}\text { Relative } \\
\text { frequency } \\
\text { error \% }\end{array}$ & $\begin{array}{c}\text { Diagonal } \\
\text { of MAC }\end{array}$ & $\begin{array}{c}\text { Natural } \\
\text { frequency } \\
(\mathrm{Hz})\end{array}$ & $\begin{array}{c}\text { Relative } \\
\text { frequency } \\
\text { error \% }\end{array}$ & $\begin{array}{c}\text { Diagonal } \\
\text { of MAC }\end{array}$ \\
\hline 1 & 13.75 & 0.012 & 14.22 & $3.42 \%$ & 0.9953 & 13.74 & $0.07 \%$ & 0.9966 \\
\hline 2 & 92.6 & 0.0033 & 92.36 & $0.26 \%$ & 0.9729 & 92.45 & $0.16 \%$ & 0.99 \\
\hline 3 & 263.4 & 0.00174 & 262.36 & $0.40 \%$ & 0.9983 & 263.27 & $0.05 \%$ & 0.9971 \\
\hline 4 & 516.84 & 0.00214 & 515.17 & $0.32 \%$ & 0.9854 & 516.82 & $0.00 \%$ & 0.99 \\
\hline 5 & 846.67 & 0.00095 & 845.68 & $0.12 \%$ & 0.9952 & 846.97 & $0.04 \%$ & 0.9978 \\
\hline 6 & 1249.03 & 0.00284 & 1235.39 & $0.11 \%$ & 0.9862 & 1251.44 & $0.19 \%$ & 0.9903 \\
\hline 7 & 1736.06 & 0.0037 & 1717.47 & $0.04 \%$ & 0.9888 & 1736.86 & $0.05 \%$ & 0.9971 \\
\hline
\end{tabular}

Table 11. Modal parameters of the beam in damaged states.

\begin{tabular}{|c|c|c|c|c|c|c|c|c|c|}
\hline \multirow{2}{*}{$\begin{array}{c}\text { Mode } \\
\text { number }\end{array}$} & $\begin{array}{c}\text { Updated } \\
\text { FE model } \\
\text { frequency } \\
(\mathrm{Hz})\end{array}$ & $\begin{array}{c}\text { Frequency } \\
(\mathrm{Hz})\end{array}$ & $\begin{array}{c}\text { Damping } \\
\text { ratio }\end{array}$ & $\begin{array}{c}\text { Relative } \\
\text { frequency } \\
\text { error } \%\end{array}$ & $\begin{array}{c}\text { Diagonal } \\
\text { of MAC }\end{array}$ & $\begin{array}{c}\text { Frequency } \\
(\mathrm{Hz})\end{array}$ & $\begin{array}{c}\text { Damping } \\
\text { ratio }\end{array}$ & $\begin{array}{c}\text { Relative } \\
\text { frequency } \\
\text { error \% }\end{array}$ & $\begin{array}{c}\text { Diagonal } \\
\text { of MAC }\end{array}$ \\
\hline 1 & 13.7406 & 13.51 & 0.019 & 1.68 & 0.9998 & 13.46 & 0.017 & 2.04 & 0.9999 \\
\hline 2 & 92.4557 & 91.57 & 0.00245 & 0.96 & 0.9972 & 89.74 & 0.00317 & 2.94 & 0.9983 \\
\hline 3 & 263.267 & 262.68 & 0.00243 & 0.22 & 0.9945 & 261.7 & 0.00294 & 0.60 & 0.994 \\
\hline 4 & 516.8238 & 516.77 & 0.00338 & 0.03 & 0.9904 & 509.18 & 0.003878 & 1.48 & 0.9813 \\
\hline 5 & 846.975 & 842.66 & 0.00128 & 0.51 & 0.9960 & 841.02 & 0.00107 & 0.70 & 0.9871 \\
\hline 6 & 1251.442 & 1239.17 & 0.00489 & 0.98 & 0.9775 & 1227.97 & 0.001925 & 1.88 & 0.9927 \\
\hline 7 & 1736.862 & 1717.63 & 0.0014 & 1.11 & 0.9962 & 1702.27 & 0.001145 & 1.99 & 0.9971 \\
\hline
\end{tabular}

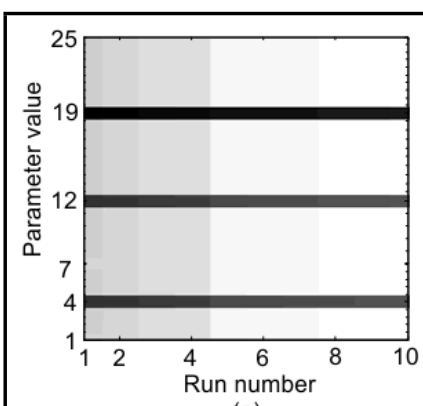

(a)

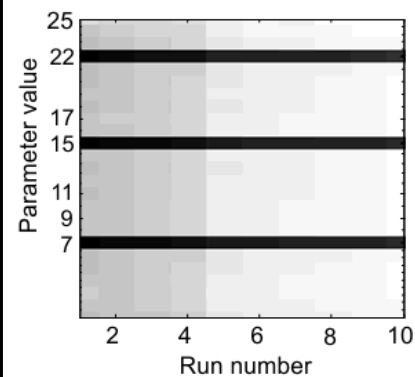

(c)

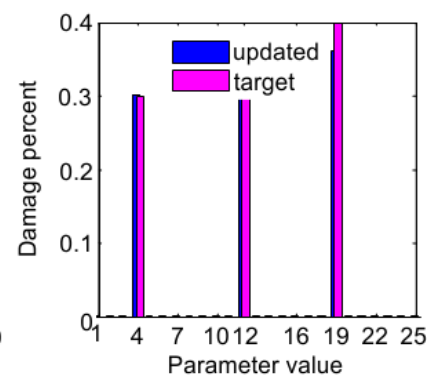

(b)

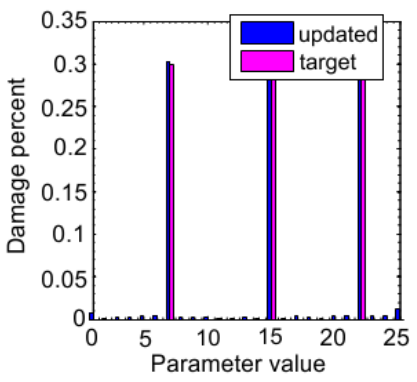

(d)

Figure 16. Results of the truss damage identification problem for damage scenario 8. (a) Graphical stiffness damage detection; (b) Stiffness damage percent for each element; (c) Graphical density damage detection; (d) Density damage percent for each element.

and double damage on the FRFs function is clearly remarkable, especially for the high frequencies. Natural frequencies are directly proportional to stiffness. The natural frequencies of the beam with double crack have reduced and are lower than the beam with single crack and the intact beam which is due to the reduction of stiffness caused by cracks.

It can be noted that if the number of crack increases, the amplitude of high frequency of FRFs also increases but the

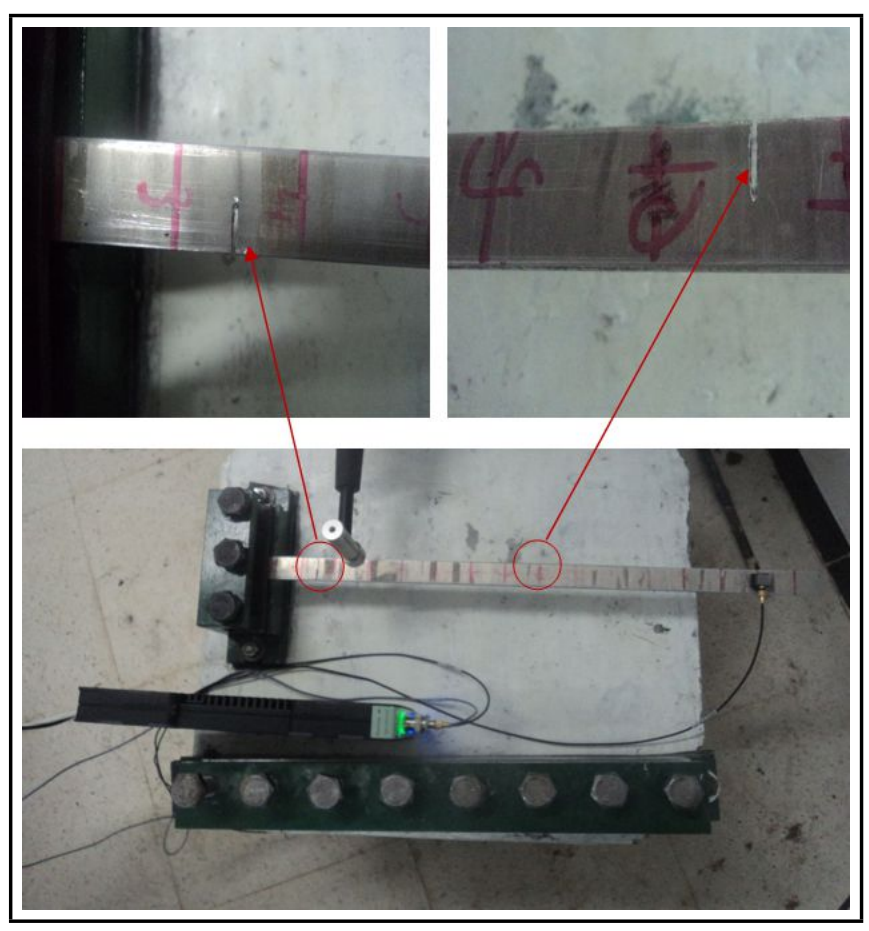

Figure 17. Experimental set-up for damaged beam with single and double cracks.

amplitude of low frequency decreases.

Table 10 show the modal parameters of the cantilever (Case1) with a single crack situated at the second element of the beam and for a double crack (Case-2) situated at the second and ninth elements.

The FE model is characterized by 16 updating parameters, i.e. one $p$-value for each element, corresponding to its stiffness matrix. The initial $p$-values are set to 1 , and the updated $p$-values are generated randomly between 0 and 1 , where the 


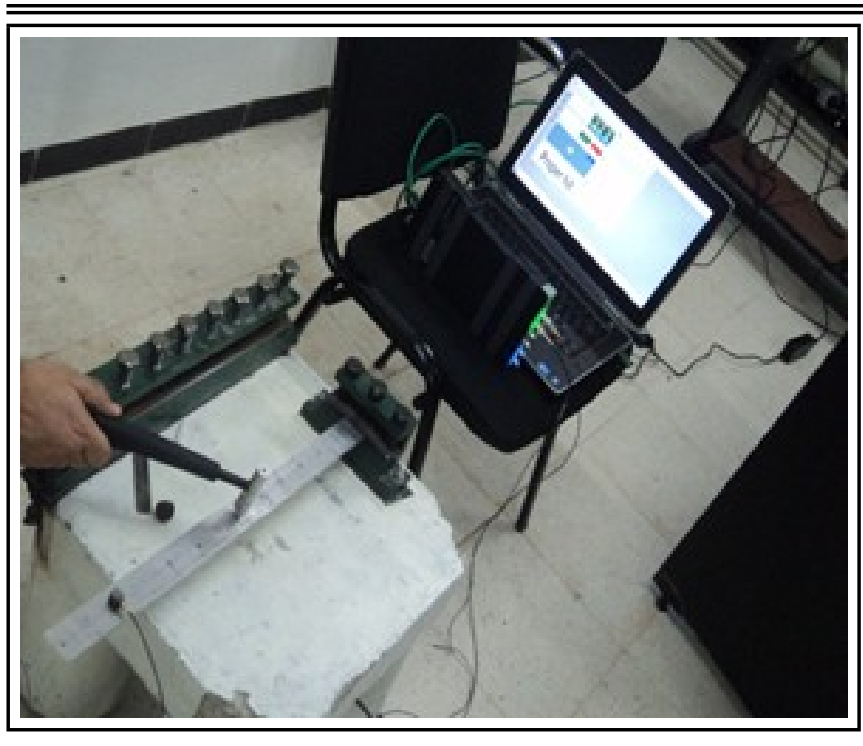

Figure 18. Experimental set-up for undamaged beam.

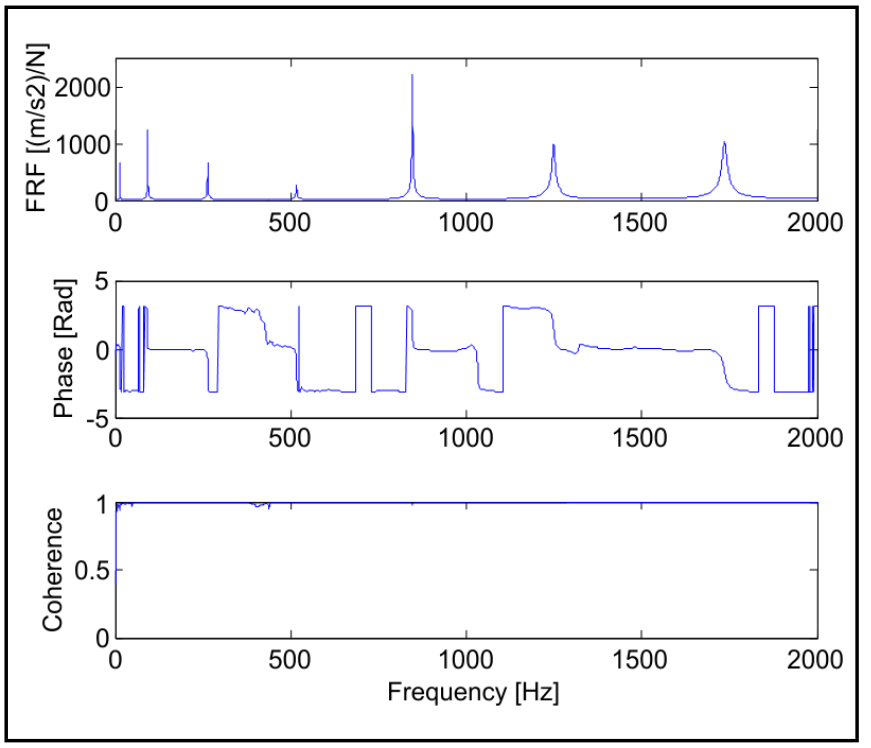

Figure 19. Experimental frequency response function, phase, and coherence for intact cantilever beam (response in point 15 for an impact in point 3 ).

value equal to 1 corresponds to no damage in structure and to no change of the parameter. By considering the stochastic process, the IMARS algorithm has been run 20 times independently. The first ten best results of model updating are then taken and applied for damage detection procedure. For case 1 (single crack), the variation of damage parameters for each run is shown in Fig. 22. The predicted stiffness damage factors of all elements are almost the same with the true values, and only element 2 is damaged (Fig. 22a). The step of quantification is performed from data of Fig. 22a. Using Eq. (16), one can compute the average vector $P_{v}$, and then Eq. (17) to compute the final parameter $\gamma_{f}$ presenting the updated FE model. The searched results of stiffness damage factor for all elements are shown in Fig. 22b. The proposed algorithm still finds the solution with high precision ( stiffness reduction $=10 \%$ approximately).

For case 2 (double crack), the searched results of stiffness damage factor for all elements are shown in Fig. 23. The proposed algorithm finds the stiffness damage reduction in element 2 of the beam with the same value (10\% approxi-

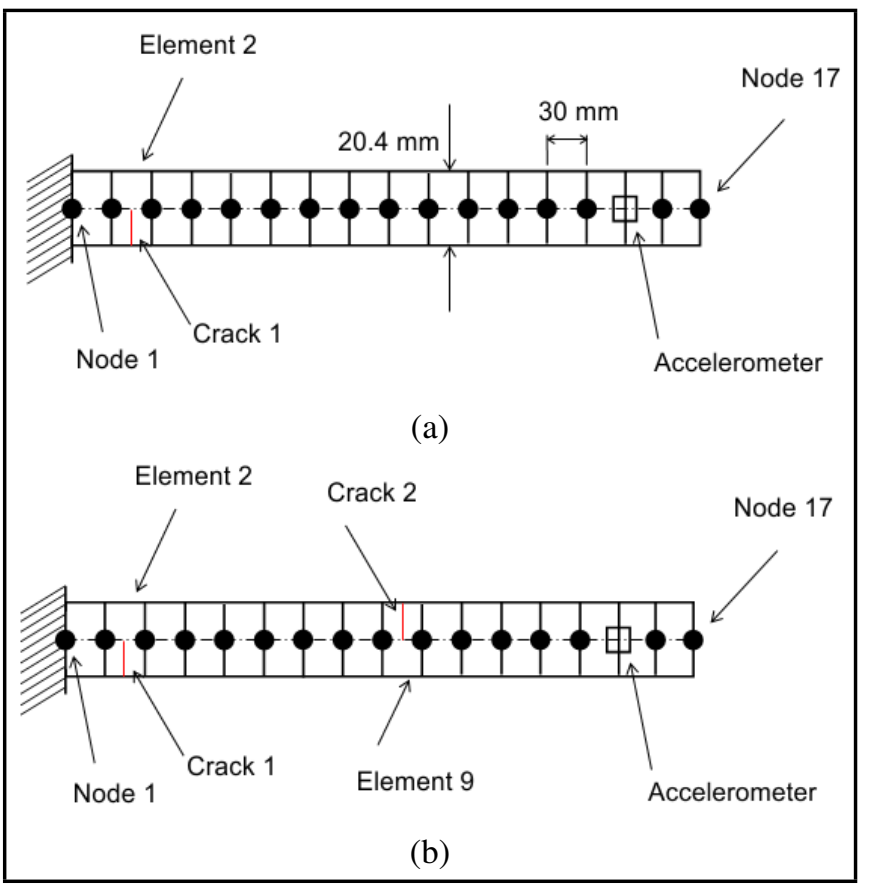

Figure 20. Finite element model and crack location in real cantilever beam. (a) Single crack; (b) Double crack;

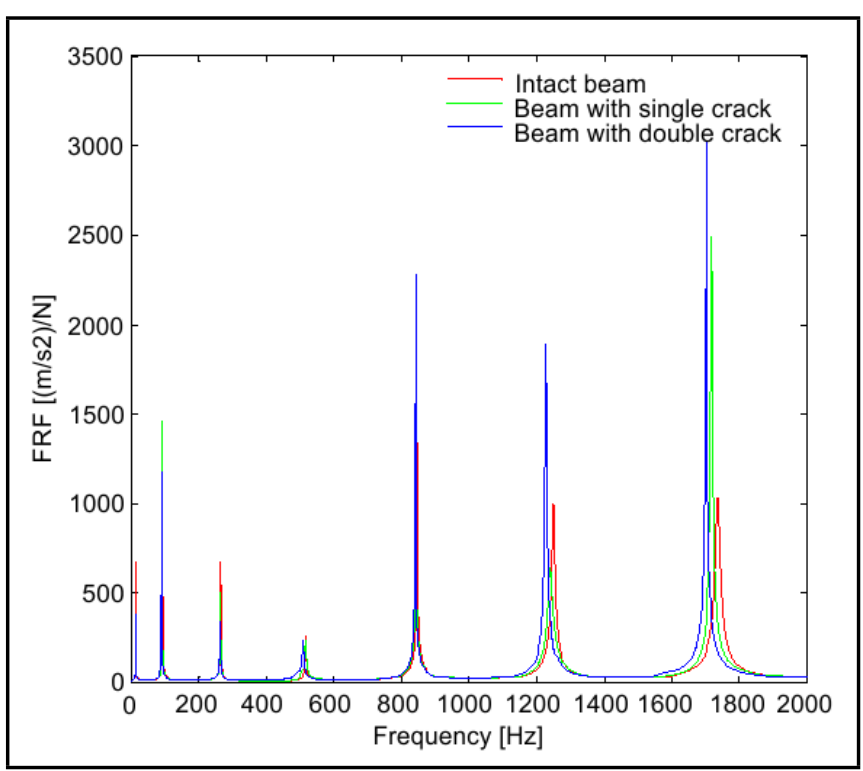

Figure 21. Frequency Response functions in case of intact, single cracked, and double cracked beam.

mately) (Fig. 23b), also for the element 9 the damage is detected (Fig. 23a). The proposed algorithm gives damage in element 8 which does not exist, the cause of this is probably due to asymmetrical position of the second crack in relation to first crack.

As the proposed method is affected from noise, measurement errors or noisy data affect directly the solution accuracy, and the noise of different measured data may have a summation effect on the searched results. So, one must take care when doing measurement, by choosing the best position of accelerometers, impact point, sampling frequency, boundary conditions, etc. Also, when using experimental vibration data for real structures, the initial finite element model of undamaged structure must first be updated to match the experimental data, which can improve the correlation between target and up- 


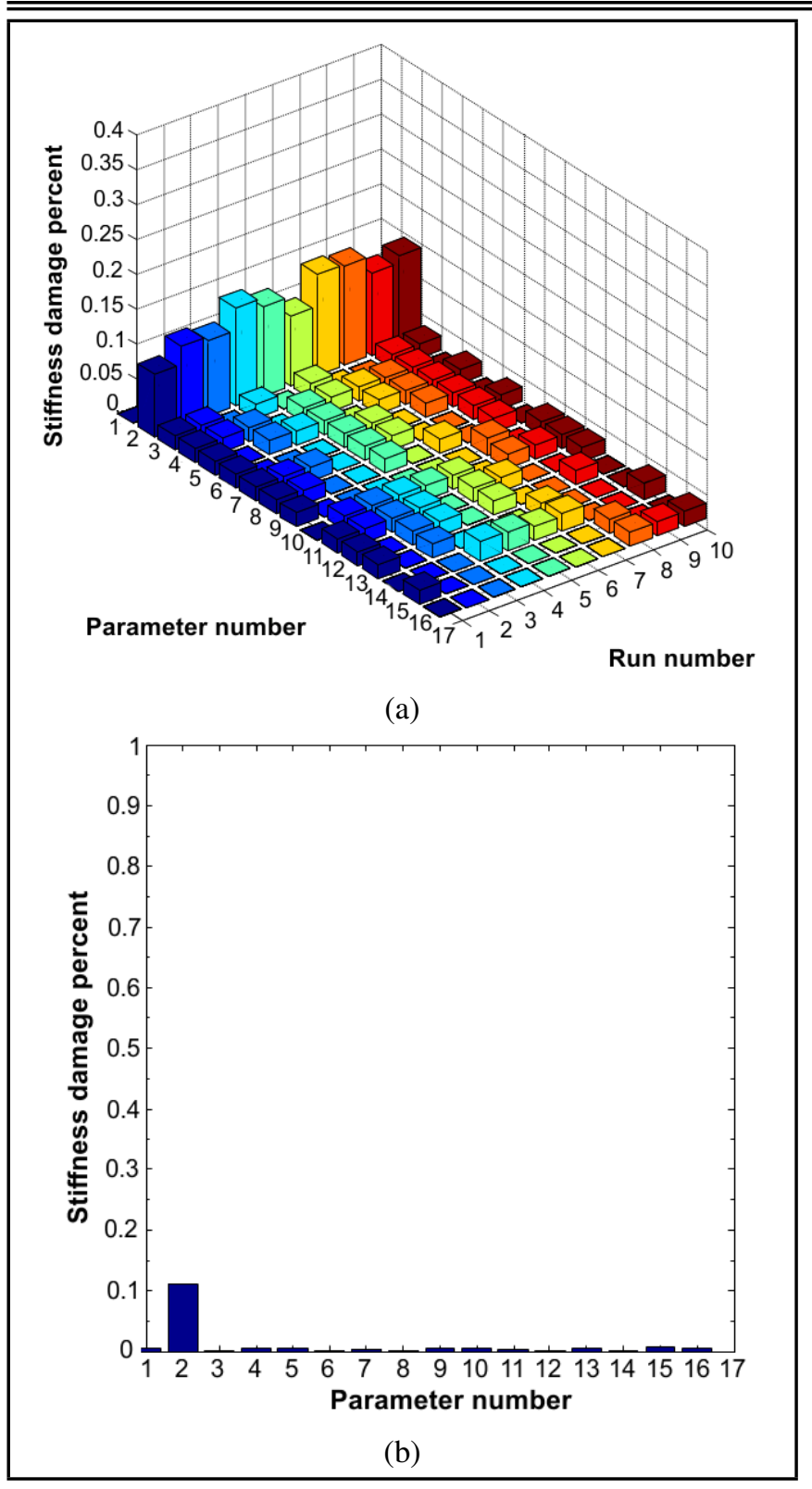

Figure 22. Results of the cantilever beam damage identification problem for single crack. (a) Graphical stiffness damage detection; (b) Stiffness damage percent for each element.

dated results.

\section{CONCLUSIONS}

In this article, a new version of ARS algorithm (IMARS) for structural damage identification detection has been presented. The damage procedure algorithm is composed of two stages. Detecting the number and localization of damaged elements by multi-run process is done in the first stage. With damage number determined, the quantification step is then applied using simple computing procedure.

The algorithm exploits the accelerated hill-climbing ability and higher probability of converging to a global solution given by ARS. The optimization ability of proposed algorithm has been verified by different functions and compared with other methods. The mathematical benchmark functions have confirmed a good capacity of the IMARS algorithm to deal with this kind of problems.

For damage detection, the approach has been applied first on

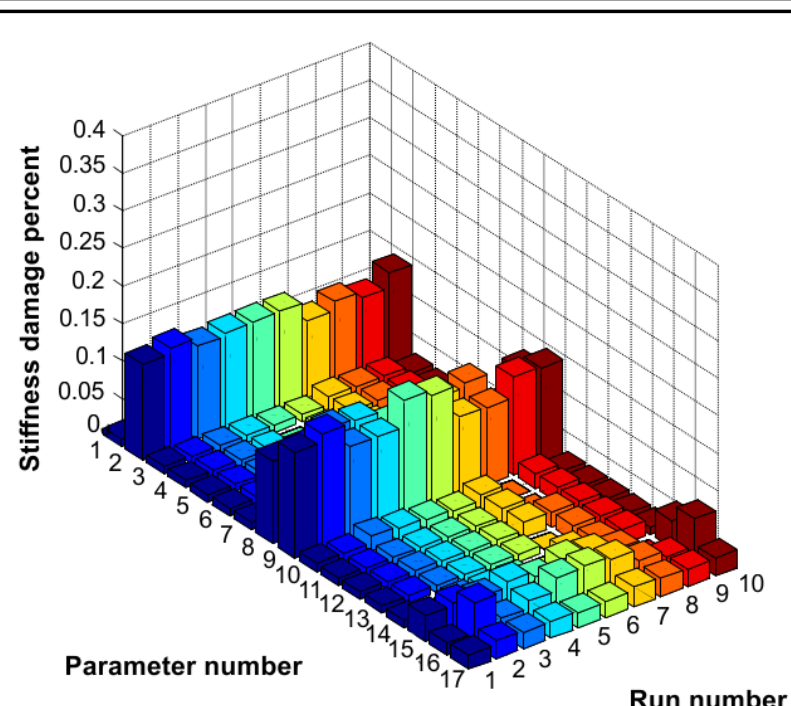

(a)

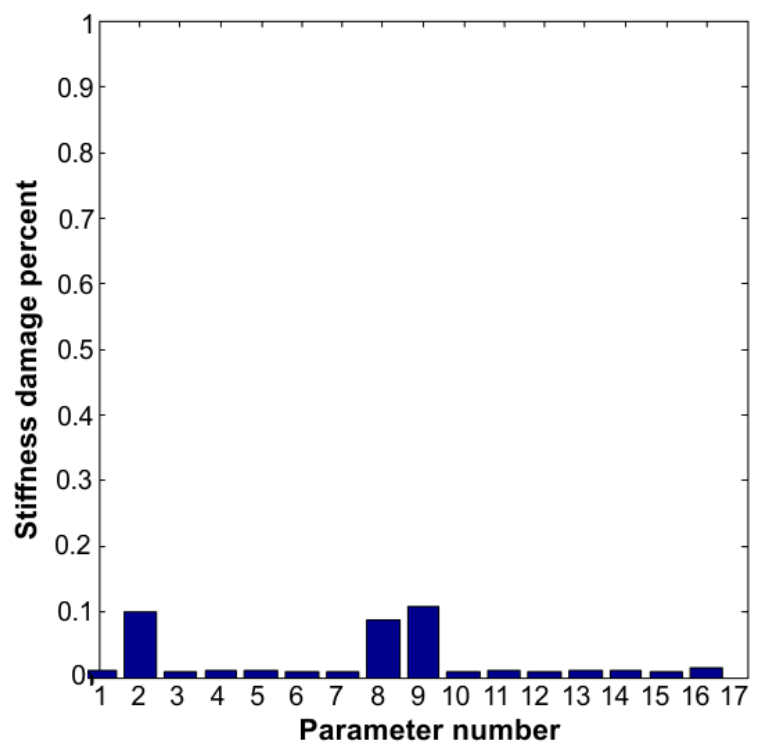

(b)

Figure 23. Results of the cantilever beam damage identification problem for double cracks. (a) Graphical stiffness damage detection; (b) Stiffness damage percent for each element.

two simulated problems. The first problem is a beam structure with multi damaged element scenarios. The second problem is a truss structure that has both flexural stiffness and mass damage occurrence. The proposed algorithm is efficient in damage identification for beam-type and truss structures with different damage scenarios and with sparse measured data. It is also shown that the proposed algorithm is effective in identifying positions and extents of multiple damage occurrences. In addition to flexural stiffness damage, it is also good in detecting mass damage. The results also show that the searched solution agrees the exact value well, when the measured data are free of noise. Even if small amount of measured data is used, the proposed algorithm still finds the solutions with high precision. When noise is added to the measured data, the damage occurrence predicted by the proposed algorithm is still in reasonable precision.

The experimental example has shown the efficiency of the proposed method to detect single and double damages in real 
structure in presence of vibration data. The use of IMARS algorithm for model updating has permitted to correct the initial finite element model of undamaged structure to match the modal tests due to modelling errors. The updated model has been then used for damage detection process of cracks for damaged structure.

\section{REFERENCES}

1 Rytter A. Vibration based inspection of civil engineering structures. PhD thesis, Department of Building Technology and Structural Engineering: Aalborg University, Denmark, 1993.

2 Doebling S. and Farrar C. Computation of structural flexibility for bridge health monitoring using ambient modal data. In Proceedings of the $11^{\text {th }}$ ASCE engineering mechanics conference, Ft. Lauderdale, FL, 1114-7, (1996).

3 Carden E. P. and Fanning P. Vibration Based Condition Monitoring: A Review, Struct. Health Monit., 4 (3), 355-377, (2004). https://dx.doi.org/10.1177/1475921704047500

4 Sophia H. and Garrett D. J. Identification of stiffness reductions using natural frequencies. J Eng Mech., 121 (10), 1106-13, (1995). https://dx.doi.org/10.1061/(ASCE)07339399(1995)121:10(1106)

5 Sheinman I. Damage detection and updating of stiffness and mass matrices using mode data. Comput Struct., 59 (1), 149-56, (1996).

6 Kosmatka J. B. and Ricles J. M. Damage detection in structures by modal vibration characterization. J Eng Mech., 125 (12), 1384-92, (1999). https://dx.doi.org/10.1061/(ASCE)07339445(1999)125:12(1384)

7 Law S. S., Chan T. H., and Wu D. Efficient numerical model for the damage detection of large. Eng Struct., 23 (5), 436-52, (2001). https://dx.doi.org/10.1016/S01410296(00)00066-3

8 Park N. G. and Park Y. S. Damage detection using spatially incomplete frequency response functions. Mech Syst Signal Process., 17 (3), 519-32, (2003). https://dx.doi.org/10.1006/mssp.2001.1423

9 Wang Z, Lin R. M., and Lim M. K. Structural damage detection using measured FRF data. Comput Methods Appl Mech Eng., 147 (1-2), 187-97, (1997). https://dx.doi.org/10.1016/S0045-7825(97)00013-3

10 Maia N. M. M., Silva J. M. M., and Almas E. A. M. Damage detection in structures: from mode shape to frequency response function methods. Mech Syst Signal Process., 17 (3), 489-98, (2003). https://dx.doi.org/10.1006/mssp.2002.1506

11 Hjelmstad K. D. and Shin S. Damage detection and assessment of structures from static response. J Eng Mech., 123 (6), 568-76, (1997) https://dx.doi.org/10.1061/(ASCE)07339399(1997)123:6(568)
12 Wang $\mathrm{X}, \mathrm{Hu} \mathrm{N}$, Fukunaga $\mathrm{H}$, and Yao Z. H. Structural damage identification using static test data and changes in frequencies. Eng Struct., 23 (6), 610-21, (2001). https://dx.doi.org/10.1016/S0141-0296(00)00086-9

13 Zimmerman D. C. and Simmermacher T. Model correlation using multiple static load and vibration tests. AIAA J, 33 (11), 2182-8, (1995). https://dx.doi.org/10.2514/3.12813

14 He R. S., Hwang S. F., Damage detection by an adaptive real-parameter simulated annealing genetic algorithm. Comput and Struct., 84 (31), 2231-2243, (2006). https://dx.doi.org/10.1016/j.compstruc.2006.08.031

15 Cawley P. and Adams R. D. The Location of Defects from Measurements of Natural Frequencies. $J$ of Strain Anal., 14(2), 49-57, (1979). https://dx.doi.org/10.1243/03093247V142049

16 Farrar C. R., Baker W. E., Bell T. M., Cone K. M., Darling T. W., Duffey T. A., Eklund A., and Migliori A. Dynamic Characteristics and Damage Detection in the I-40 Bridge over the Rio Grande. Los Alamos National Laboratory Report LA-12767-MS, 1994.

17 Salawu O. Detection of structural damage through changes infrequency: a review. Eng. Struc., 19 (9), 718-723, (1997). https://dx.doi.org/10.1016/S0141-0296(96)00149-6

18 Wang R., Shang D., Li L., and Li C. Fatigue Damage Model Based on the Natural Frequency Changes for Spotwelded Joints. Intl J of Fatigue, 30 (6), 1047-1055, (2008). https://dx.doi.org/10.1016/j.ijfatigue.2007.08.008

19 Zhong S. and Oyadiji S. O. Analytical Predictions of Natural Frequencies of Cracked Simply Supported Beams with a Stationary Roving Mass. J of Sound and Vib., 311 (1), 328352, (2008). https://dx.doi.org/10.1016/j.jsv.2007.09.009

20 Zhong S., Oyadiji S. O., and Ding K. Response-only Method for Damage Detection of Beam-like Structures Using High Accuracy Frequencies with Auxiliary Mass Spatial Probing. J of Sound and Vib., 311 (3), 1075-1099, (2008). https://dx.doi.org/10.1016/j.jsv.2007.10.004

21 Salawu O. S. Non-destructive Assessment of Structures Using Integrity Index Method Applied to a Concrete Highway Bridge. Insight, 37 (11), 875-878, (1995).

22 Esfandiari A., Bakhtiari-Nejad F., Rahai A., and Sanayei M. Structural Model Updating Using Frequency Response Function and Quasi-linear Sensitivity Equation. $J$ of Sound and Vib., 326 (3), 557-573, (2009). https://dx.doi.org/10.1016/j.jsv.2009.07.001

23 Lee J. and Kim S., Structural Damage Detection in the Frequency Domain Using Neural Networks. J of Intell Mater Syst and Struct., 18 (8), 785-792, (2007). https://dx.doi.org/10.1177/1045389X06073640

24 Friswell M. I. and Mottershead J. E. Finite Element Model Updating in Structural Dynamics. Kluwer Academic Publishers Group, Norwell, (1995). 
25 Mottershead J. E. and Friswell M. I. Model Updating in Structural Dynamics: A Survey. $J$ of Sound and Vib., 167, 347-375, (1993). https://dx.doi.org/10.1006/jsvi.1993.1340

26 Levin R. I. and Lieven N. A. J. Dynamic Finite Element Model Updating using Simulated Annealing and A genetic algorithms. Mech Syst and Signal Process., 12, 91-120, (1998). https://dx.doi.org/10.1006/mssp.1996.0136

27 Fan W. and Qiao P. Vibration-based Damage Identification Methods: A Review and Comparative Study, Struct. Health Monit., 10 (1), 83-111, (2011). https://dx.doi.org/10.1177/1475921710365419

28 Maia N. M. M. and Silva J. M. M. Theoretical and Experimental Modal Analysis. Research Studies Press, Letchworth, (1997).

29 Teughels A., De Roeck G., and Suykens, J. A. K. Global optimization by Coupled Local Minimizers and its application to FE model updating. Comput and Struct., 81 (2425), 2337-2351, (2003). https://dx.doi.org/10.1016/S00457949(03)00313-4

30 Teughels, A. and De Roeck, G. Damage detection and parameter identification by finite element model updating. Archives of Comput Methods Eng., 12 (2), 123-164, (2005). https://dx.doi.org/10.1007/BF03044517

31 Reynders, E., Teughels, A., and De Roeck, G. Finite element model updating and structural damage identification using OMAX data. Mech Syst Signal Process., 24 (5), 1306-1323, (2010). https://dx.doi.org/10.1016/j.ymssp.2010.03.014

32 Vincenzi L., Roeck G., De., and Savoia M. Comparison between coupled local minimizers method and differential evolution algorithm in dynamic damage detection problems. Advances Eng Software., 65, 90-100, (2013). https://dx.doi.org/10.1016/j.advengsoft.2013.06.001

33 Marwala T. Finite Element Updating Using Wavelet Data and A genetic algorithm. AIAA J of Aircr., 39 (4), 709-711, (2002).

34 Marwala T. Control of Fermentation Process Using Bayesian Neural Networks and A genetic algorithm. In Proc of the African Control Conf, 449-454, (2003). https://dx.doi.org/arXiv:0705.1214

35 Marwala T. Finite Element Model Updating Using Response Surface Method. 45 AIAA/ASME/ASCE/AHS/ASC Structures, Structural Dyn \& Mater Conf: Paper AIAA-2004-2005.

36 Touat N., Pyrz M., and Rechak S. Accelerated random search method for dynamic FE model updating. Eng. Comput., 24 (5), 450-472, (2007). https://dx.doi.org/10.1108/02644400710755861

37 Appel M. J., Labarre R., and Radulovic D. On Accelerated Random Search. SIAM Journal on Optim., 14 (3), 708-731, (2004). https://dx.doi.org/10.1137/S105262340240063X
38 Meruane, V. and Heylen, W. Damage detection with parallel genetic algorithms and operational modes, Struc. Health Monit., 9 (6), 481-496, (2010). https://dx.doi.org/10.1177/1475921710365400

39 Borges, C. C. H., Barbosa, H. J. C., and Lemonge, A. C. C. A structural damage identification method based on genetic algorithm and vibrational data, International journal for numerical methods in engineering, 69 (13), 2663-2686, (2007) https://dx.doi.org/10.1002/nme.1857

40 Pan, D. G., Lei, S. S., and Wu, S. C. Two-stage damage detection method using the artificial neural networks and genetic algorithms, Lect. Notes Comput. Sci., 6377 (325332), (2010). https://dx.doi.org/10.1007/978-3-642-16167$4 \_42$

41 Jeong, M., Choi, J. H., and Koh, B. H. Performance evaluation of modified genetic and swarm-based optimization algorithms in damage identification problem, Struct. Control Health Monit., 20 (6), 878-889, (2011). https://dx.doi.org/10.1002/stc.507

42 He, R. S. and Hwang, S. F. Damage detection by an adaptive real-parameter simulated annealing genetic algorithm, Comput. Struct, 84 (31-32), 2231-2243, (2006). https://dx.doi.org/10.1016/j.compstruc.2006.08.031

43 Xiang, J., Liang, M., and He, Y. Experimental investigation of frequency-based multi-damage detection for beams using support vector regression, Engineering Fracture Mechanics, 131, 257-268, (2014) https://dx.doi.org/10.1016/j.engfracmech.2014.08.00

44 Kirkpatrick, S., Gelatt, C., and Vecchi, M. Optimization by simulated annealing, Science, 220 (4598), 671-680, (1983).

45 Schwefel, H. P., Numerical Optimization of Computer Models, Wiley \& Sons, Chichester, (1981).

46 Leung Y. W. and Wang Y. An Orthogonal Genetic Algorithm with Quantization for Global Numerical Optimization. IEEE Trans. Evol. Comput., 5 (1), 41-52, (2001). https://dx.doi.org/10.1109/4235.910464

47 Kwon K. S. and Lin R. M. Robust Finite element model updating using Taguchi method. J of Sound and Vib., 280 (1), 77-99, (2005). https://dx.doi.org/10.1016/j.jsv.2003.12.013

48 Kim G. H. and Park Y. S. An improved updating parameter selection method and finite element model update using multi-objective optimization technique. Mech Syst and Signal Process, 18 (1), 59-78, (2004). https://dx.doi.org/10.1016/S0888-3270(03)00042-6

49 Lei, Y. and Jiang, Y., and Xu, Z. Structural damage detection with limited input and output measurement signals, Mechanical Systems and Signal Processing, 28, 229-243, (2012). https://dx.doi.org/10.1016/j.ymssp.2011.07.026 